\title{
La adaptación al Espacio Europeo de Educación Superior, 13 años después: la destrucción del saber en las universidades españolas
} Adaptation to the European Higher Education Area, after 13 years: the destruction of knowledge at Spanish universities

\author{
Esther Pomares Cintas \\ Universidad de Jaén \\ ORCID ID 0000-0001-6533-6873 \\ epomares@ujaen.es \\ Francisco Javier Álvarez García
Universidad Carlos III de Madrid
ORCID ID 0000-0001-6052-6598
franciscojavier.alvarez@uc3m.es
}

Cita recomendada:

Pomares Cintas, E. y Álvarez García, F.J. (2020). La adaptación al Espacio Europeo de Educación Superior, 13 años después: la destrucción del saber en las universidades españolas. Eunomía. Revista en Cultura de la Legalidad, 19, pp. 184-213.

doi: https://doi.org/10.20318/eunomia.2020.5708

Recibido / received: 17/07/2020 Aceptado / accepted: 18/08/2020

\section{Resumen}

Exponen los autores la evolución de la Universidad pública española a lo largo de los últimos treinta años, subrayando cómo el interés por convertir los estudios superiores en un objeto más de obtención de beneficios llevó en Europa a los grupos inversores internacionales a una transformación de la Universidad que se plasmó en el «Plan de Bolonia». Este modelo se integra dentro del objetivo del «mercado común» europeo, o lo que es lo mismo, concibe la Universidad como una «mercancía» más. En ese sentido, el «sistema Bolonia» ha servido de plataforma idónea para canalizar inversiones capaces de generar prontos réditos y recuperaciones de la inversión: disminuye la duración de los estudios y su profundidad, construyendo los planes sobre la base de conocimientos genéricos y «muy prácticos», con capacidad de «intercambio en el 
mercado». Encarna un cambio de paradigma de perfil empresarial en doble dirección: el estudiante como cliente y la figura burocratizada del docente-dador de clases.

La idea de una Universidad entendida como una mera «formación profesional» despojada de cualquier inquietud transformadora del mundo se ha desarrollado en España bajo el auge de universidades privadas, impulsadas desde mediados de la década de los 90 , que ha contribuido a deteriorar gravemente la calidad de la enseñanza, pervirtiendo, asimismo, el sistema de recluta del profesorado hasta lograr convertirlo en funcional a ese modelo: un procedimiento radicalmente burocrático, en el que tiene un peso específico el perfil del docente en tareas muy alejadas de la docencia e investigación, cuya producción se sujeta a valoraciones preeminentemente formales basadas en decisiones editoriales. Ello ha provocado una multiplicación de publicaciones bajo la lógica de la «uniformidad» y, sobre todo, la «funcionalidad» al mercado. Paralelamente, con la indisimulada intención de impulsar los centros privados, se ha recortado el presupuesto de las universidades públicas, el de la investigación en los centros públicos, y se ha precarizado al profesorado universitario hasta límites inaceptables. La Universidad pública, condenada al ostracismo.

Los autores ponen de relieve la necesidad de llevar a cabo, con fondos públicos, un rescate urgente de la Universidad española pública, para restaurarla desde sus cimientos y que pueda, así, contribuir a un cambio de modelo de desarrollo económico del que tan necesitada está España, que incluso permitirá sobrevivir con mayor solvencia a futuras pandemias.

\section{Palabras clave}

Rescate de la Universidad pública, Mercado común europeo, Plan Bolonia, Universidad virtual, universidades privadas, selectividad, calidad del profesorado universitario, ANECA, reforma universitaria.

\section{Abstract}

The authors present the evolution of the Spanish Public University over the last thirty years, underlining how the interest in making higher education an object of further profit-making led international investment groups in Europe to a transformation of the University that was embodied in the "Bologna Plan». This model fits into the objective of the European «common market», or what is the same, conceives the university as just another commodity. In this sense, the "Bologna system» has served as an ideal platform for channelling investments capable of generating early returns and recoveries from investment: it reduces the duration of studies and their depth, building the plans on the basis of generic knowledge and "very practical», with the ability to "exchange in the market». It embodies a paradigm shift of business profile in two directions: the student as client and the bureaucratized figure of the teacher-giver of classes.

The idea of a university understood as a mere «vocational training» deprived of any transformative initiative of the world has developed in Spain under the rise of private universities, driven since the mid-1990s, which has contributed to a serious deterioration in the quality of teaching and has also perverted the system of recruiting teaching staff to the point of making it functional: a radically bureaucratic procedure, in which the teacher's profile in tasks very different from teaching and research has a specific weight, whose production is subject to pre-eminently formal valuations based on editorial decisions.

This has led to a multiplication of publications under the logic of "uniformity» and, above all, market «functionality». At the same time, with the clearly intended of boosting private institutions, the budget of public universities, and the research in public institutions, has been cut, and university teaching staff has been made precarious to unacceptable limits. The public university, ostracized. The authors emphasize the need to carry out, with public funds, an urgent rescue of the public Spanish University, in order to restore it from its foundations and thus contribute to a change in the economic development model that Spain needs, which will even allow to survive future pandemics with greater solvency.

\section{Keywords}

Rescue of Public University, European "common market», Bologna Plan, virtual university, private universities, selectivity process, quality of the university's teaching staff, ANECA, university reform. 


\begin{abstract}
SUMARIO. 1. El «Acervo» de Bolonia y el Espacio Europeo de Educación Superior (EEES). 1.1. La reforma universitaria española y la problemática adaptación al sistema EEES. 1.1.1. La reestructuración de la formación universitaria bajo el eje de la liberalización: una convergencia a la baja. 1.1.2. La Universidad pública como empresa (privada). 1.2. Perfil del alumnado y del profesorado universitario adaptado al sistema de los créditos ECTS. 1.3. El docente comprometido con el conocimiento también es víctima del sistema. 2 . Adaptación de la Universidad al sistema de mercado: la función de educar como herramienta. 3. ¿Una nueva reforma? Proyecto de Real Decreto por el que se establece la ordenación de las enseñanzas oficiales del Sistema Universitario Español. 4. De templo del saber a negocio indisimulado: la Universidad como una commodity más. 4.1. La instalación de las universidades privadas en España. 4.2. Las nuevas "universidades basura". 4.3. La apuesta de los inversores por los estudios universitarios. 4.4. La Universidad on line, pieza funcional del sistema: la muerte de la implicación del docente en la enseñanza universitaria. La distancia para todo. 4.5. A modo de conclusión de este epígrafe. 5. La reducción de la duración de las licenciaturas y sus precedentes. 6. La transformación de los estudiantes. 6.1. Las pruebas de acceso a la Universidad. 6.2. Selectividad de «clase». 6.3. El Estado Social abandonado. 7. El cambio en el acceso a la función del profesorado universitario. 7.1. Introducción. 7.2. Historia antigua. 7.3. La Edad moderna. 7.4. La Edad contemporánea: sistema de acreditaciones ANECA. 7.5. La precarización del profesorado universitario en la Universidad pública. 8. A modo de conclusión: hacia el rescate de la Universidad pública española.
\end{abstract}

\title{
1. El «acervo» de Bolonia y el Espacio Europeo de Educación Superior (EEES)
}

La Universidad española ha experimentado una profunda metamorfosis en los últimos 20 años, condicionada por la Declaración de Bolonia de 19 de junio de 1999 y la irrupción del sistema EEES (la Estrategia de Lisboa, 2001), que condujeron a la sustitución de la Ley Orgánica 11/1983, de 25 de agosto, de Reforma Universitaria (LRU), por la Ley Orgánica 6/2001, de 21 de diciembre, de Universidades (LOU), y su posterior reforma por la Ley Orgánica 4/2007, de 12 de abril, como exigencia de adaptación al nuevo espacio educativo europeo.

A partir de la Declaración de la Sorbona de 25 de mayo de 1998, se inicia un proceso de aproximación de los sistemas nacionales de educación superior de los Estados miembros de la Unión Europea, cuyo impulso definitivo tiene lugar con la Declaración de Bolonia de 19 de junio de 1999¹. El objetivo principal de ambas era promover la creación de un Espacio Europeo de Educación Superior que permitiría la homologación y el reconocimiento de Títulos, requisito imprescindible para una libre circulación de ciudadanos europeos de formación cualificada capaz de incrementar la competitividad económica en el mercado europeo.

\footnotetext{
${ }^{1}$ Vid. http://www.eees.es/pdf/Bolonia_ES.pdf.
} 
1.1. La reforma universitaria española y la problemática adaptación al sistema EEES

Con objeto de amoldar las estructuras de los estudios al EEES, las modificaciones decisivas se llevaron a cabo a partir de la Ley Orgánica 6/2001, de 21 de diciembre, de Universidades (LOU), que emprende un proceso de reestructuración a través de los siguientes ejes funcionales:

- Un sistema educativo dividido en ciclos (Grado, Master y Doctorado), que implica un particular sistema de créditos y la implantación de nuevas metodologías docentes.

- Liberalización de los Planes de Estudios de las Titulaciones.

- Creación de mecanismos externos de evaluación de la calidad de los programas y enseñanzas de las Universidades.

- El establecimiento de un sistema de evaluaciones/acreditaciones positivas en torno a diferentes perfiles laborales de personal docente e investigador, que se consolida a través de la Ley Orgánica 4/2007, de 12 de abril, por la que se modifica la Ley Orgánica 6/2001, de 21 de diciembre, de Universidades: colaborador, ayudante doctor, contratado doctor, asociados.

- Creación de mecanismos institucionales externos de evaluación de la calidad de la actividad investigadora, docente y de gestión: especialmente, la Agencia Nacional de la Evaluación de la Calidad y Acreditación (ANECA) a nivel nacional, y las agencias evaluadoras de las Comunidades Autónomas².

La integración del sistema universitario español en el EEES, a partir de las premisas marcadas por la LOU, se completa por efecto de otras herramientas legislativas, entre ellas:

- Real Decreto 1125/2003, de 5 de septiembre, por el que se estableceel sistema europeo de créditos y el sistema de calificaciones en las titulaciones universitarias de carácter oficial y validez en todo el territorio nacional.

- Real Decreto 1393/2007, de 29 de octubre, por el que se establece la ordenación de las enseñanzas universitarias oficiales (modificado por Real Decreto 861/2010, de 2 de julio, Real Decreto 43/2015, de 3 de febrero, y otros posteriores), que establece la ordenación de las enseñanzas universitarias oficiales adaptadas al EEES.

- Real Decreto 99/2011, de 28 de enero, por el que se regulan las enseñanzas oficiales de doctorado (modificado por Real Decreto 43/2015 de 3 de febrero).

- Real Decreto 412/2014, de 6 de junio, por el que se establece la normativa básica de los procedimientos de admisión a las enseñanzas universitarias oficiales de Grado.

\footnotetext{
${ }^{2}$ Véase la Ley 15/2014, de 16 de septiembre, de racionalización del sector público y otras medidas de reforma administrativa.
} 
1.1.1. La reestructuración de la formación universitaria bajo el eje de la liberalización: una convergencia a la baja

En realidad, la pretensión de facilitar la movilidad de los estudiantes y profesionales en el espacio europeo no se compadece bien con un proceso de convergencia que no buscaba una equiparación de estructuras o contenidos (Belloso Martín, 2009, pp. 219-251). En España, las Universidades renunciaron a una regulación uniforme de los planes y contenidos en cada Titulación. Se liberalizaron los Planes de Estudio bajo una misma «consigna»: la configuración del Grado -como sustituto de la Licenciatura- debía recortarse y apoyarse sobre una formulación académica generalista en la etapa inicial, basada en conocimientos generales que orientarán a la preparación profesional (Real Decreto 1393/2007, de 29 de octubre) y durante un tiempo que también se reduce. Se ofrece una «formación general» por debajo del acervo formativo. Una convergencia a la baja.

El procedimiento de adaptación estuvo viciado desde el inicio, en la medida en que se llevó a cabo presidido por la idea de liberalizar -bajo la premisa de distribución de una cantidad de créditos asociados a cada Grado- los propios planes de estudio de los Grados. Así, las facultades emprendieron una carrera contrarreloj bajo la prevalencia de tres ejes:

- Competitividad entre las propias Universidades públicas: las asignaturas ofertadas y su distribución variaban de una a otra.

- Competitividad respecto de la Universidad privada a la hora de la oferta de Grados y su extensión.

- Lucha por cuotas de créditos en la esfera interna de cada Facultad, dentro de una misma Universidad. Dada la amenaza cierta del recorte de contenidos del Grado y de su duración, los departamentos se lanzaron a una dura negociación -cuerpo a cuerpo- por preservar cuotas de presencia en los Planes de estudios ${ }^{3}$.

De lo que al parecer se trata es de repartirse un botín -los llamados «créditos»- entre las diversas áreas o departamentos, pues cada uno (cada representante de los mismos) supone que su poder académico depende (o dependerá en el futuro) de eso (Atienza Rodríguez, 2009).

- Los resultados de las negociaciones podían conducir -solo con el objetivo matemático de ajustarlas- a un Plan de Estudios basado en el desconcierto y el desbarajuste de asignaturas recortadas, dado que lo que debiera ser lo más importante -el diseño de los estudios de los alumnos- no era, frecuentemente, lo considerado más trascendente por los «negociadores», puesto que el objeto real de la pugna eran las cuotas de poder de los profesores ${ }^{4}$.

Verbigracia: en la elaboración de los Planes de Estudios de la Titulación de Derecho de la Universidad de Jaén, se realizaron gestiones para tratar de trasladar, por motivos de necesidad de madurez jurídica previa de los alumnos, la asignatura «Derecho Penal- Parte General» al Segundo Curso. Tras una propuesta en ese sentido y la correspondiente discusión en el seno de la Comisión, no se logró ese objetivo por no «cuadrar» dicha incorporación con la suma de créditos por cuatrimestre y año académico. Dada la importancia fundamental del Derecho Penal

\footnotetext{
3 Ciertamente estas «luchas» ya se habían visto anteriormente en algunas licenciaturas de «reciente» implementación, no así en las que arrastraban planes de estudios desde la década de los 50 o 60 del pasado siglo.

${ }_{4}$ Nada les importó a los catedráticos apiñar en un solo curso un buen número de asignaturas fundamentales, si con ello lograban mantener una buena parcela de influencia para sus asignaturas. Véase Laporta San Miguel (2010, pp. 7 y ss.).
} 
para la carrera de Derecho, desdoblar la asignatura en dos períodos (como se había hecho en el Plan previo al del 2002) no se ajustaba tampoco a la distribución numérica del nuevo sistema de créditos a repartir entre los cursos académicos, una opción que bloqueaba, además, la posibilidad de mantener una asignatura como Derecho penal económico. Pues bien, el resultado del acceso prematuro a la asignatura no es sino una enorme bolsa de frustración para superar una de las materias más complejas de la carrera, lo que acarrea, a su vez, problemas para poder acceder con solvencia al resto de las disciplinas ligadas con el Derecho Penal.

\subsubsection{La Universidad pública como empresa (privada)}

Partiendo de estas premisas, se encapsulan los contenidos genéricos del Grado para integrar lo que se ha entendido por «contenidos específicos» (muchos de ellos ya se encontraban incorporados en las Licenciaturas de sistemas anteriores) bajo la modalidad de Master, un ciclo de formación especializada y "privativa», inspirada en la «rentabilidad» aplicada también a la Universidad pública: se liberalizan los precios en todo el territorio nacional, que varían según Universidad, y lanzan a la Universidad pública a la carrera de la competitividad con la Universidad privada, transformando al alumnado que puede acceder al Postgrado en «clientela» de la Universidad. Un grave retroceso que convierte en «elitista» un sistema de especialización (Postgrado) que, por otra parte, tampoco garantiza un saber integral, sólo sesgado. Es un modo de convertir la enseñanza universitaria, particularmente en la Universidad pública que debía ser la depositaria de la calidad-, en un servicio privativo: una manifestación más del deterioro y privatización del sistema educativo público, que discurre paralelo al deterioro del resto de los servicios públicos esenciales ${ }^{5}$.

Dado que la enseñanza universitaria se gestiona tras la lógica mercantil, desregulando la oferta de titulaciones y liberalizando los precios del Postgrado, la Universidad como institución se somete a la estricta vigilancia del mercado, a la evaluación de las titulaciones a través de las agencias externas, "guardianas de la calidad», la European Association for Quality Assurance in Higher Education (ENQA) a nivel europeo y la ANECA y las Agencias Autonómicas en España. La ANECA, a través del Programa VERIFICA, propone criterios ajenos al mundo académico y propios del ámbito económico tales como la inserción laboral de los titulados, la presencia de docentes en contacto con el sector profesional o la «demanda social» de las titulaciones, en definitiva, su adaptabilidad a las "demandas» del sistema neoliberal: un paradigma de «calidad» que dificulta la subsistencia de títulos ajenos a esa lógica (Belloso Martín, 2009, pp. 219 y ss.) $)^{6}$. A su vez, el sistema ANECA, con sus estrategias de retroalimentación basadas en la implementación de «sellos de calidad» y "certificados de excelencia» orientados a una Universidad pública concebida como empresa (privada), comienza a burocratizar de modo interminable los procesos de evaluación, despilfarrando recursos en tareas absolutamente absurdas y banales. A eso se ha dedicado la Universidad desde el proceso de adaptación al Plan Bolonia: recuérdese la pérdida de un tiempo valioso y de dinero tras el auge de los

\footnotetext{
${ }^{5}$ El aparato normativo de que se han dotado las administraciones educativas en España, para salvaguardar la correcta implementación del EEES, les permite depurar convenientemente cualquier atisbo de "rebeldía» frente a esa nueva concepción de la Universidad como empresa. Las autoridades autonómicas competentes y la propia ANECA se encargan de comprobar si las memorias de creación /verificación de las titulaciones satisfacen «los intereses socioeconómicos de la Comunidad Autónoma», las «necesidades del mercado», si fomentan «el espíritu emprendedor y el autoempleo» y, por supuesto, si son, además, viables económicamente (vid., por ejemplo, la Orden de 20 de marzo de 2012, que desarrolla el Decreto 222/2011, de 2 de diciembre, sobre autorización de titulaciones oficiales en el Sistema Universitario de Galicia).

${ }^{6}$ Téngase en cuenta la lamentable pérdida de peso del Área de las Humanidades por su falta de reflejo en los mercados.
} 
Congresos «pedagógicos» y cursos sobre los métodos docentes -y la inversión presupuestaria que supuso- para enseñar la premisa: el recorte de la propia formación universitaria y la precarización de la calidad de la Universidad española.

En síntesis, asistimos a un modelo que aplica a la Universidad pública, a la enseñanza universitaria, un filtro mercantilista bajo el eje prioritario de la «rentabilidad» de un servicio público esencial. La adaptación al plan Bolonia ha servido para canalizar sin tapujos ese paradigma, invadiendo con él las entrañas de la función de la enseñanza pública superior (Moreno, 2009) 7 .

La implantación del sistema EEES ha caminado de modo paralelo al discurso de la crisis económica del último decenio y la política de austeridad en el gasto público impulsada desde la Unión Europea, que ha afectado gravemente al sistema educativo: a la Universidad pública. Ha generado un escenario neurótico en términos de competitividad entre las Titulaciones y Másteres de las universidades públicas y entre éstas y las privadas, hasta el punto de mercantilizar la formación básica del estudiante a través de la «negociación» de los planes de estudios dejados en manos de las propias universidades. Los Planes de Estudios recortan asignaturas de formación básica para el entendimiento global de la Titulación, reservando contenidos a los Programas de especialización en la forma de Másteres financiados por el alumnado. En consecuencia, hay menos créditos para repartir (menos asignaturas de la Titulación) y, bajo el pretexto de la crisis, se socializan las pérdidas mediante el aumento de la carga docente ${ }^{8}$. A su vez, la adaptación al sistema EEES mediante la LOU y la Ley Orgánica 4/2007, de 12 de abril, y su acervo posterior al hilo del «modelo económico de la crisis», condujo al "recorte de las plantillas del profesorado», a la resistencia por la Universidad pública a las contrataciones de carácter permanente, al cierre de la Universidad a las nuevas generaciones ${ }^{9}$, la disminución de Doctorados y del estímulo para emprender la carrera académica. Efectos drásticos que no garantizan, en ese contexto, la calidad: al contrario.

Por último, el «acervo de Bolonia», formado por un conjunto de comunicados y declaraciones posteriores, persigue también un cambio de lenguaje en el sistema educativo, interviniendo en la «calidad» e «idoneidad» de los métodos docentes.

1.1.2. Perfil del alumnado y del profesorado universitario adaptado al sistema de los créditos ECTS

La integración del sistema EEES invade también otros espacios, los reservados al plano de la impartición de la docencia universitaria: pretende cambiar el paradigma desde el que situar al profesor en relación con la transmisión de conocimientos y en relación con el alumnado. Se desplaza el elemento central al «proceso de aprendizaje», que trasciende el de la enseñanza de conocimientos. Ese proceso "pedagógico» se desglosa a través de un vocabulario que se "obliga» a incorporar en la elaboración de los Planes de Estudios y las Guías Docentes de las asignaturas: «resultados de aprendizaje»/«destrezas»/«competencias» (Recomendación 2008/C 111/01/CE, del Parlamento Europeo y del Consejo, de 23 de abril de 2008, relativa a

\footnotetext{
7 Véanse algunos criterios de los «Contratos-Programa», como fuente de financiación de los Departamentos, basados también en el porcentaje de aprobados de la clientela -alumnos.

${ }^{8}$ En este sentido, el Real Decreto-Ley 14/2012, de 20 de abril, de medidas urgentes de racionalización del gasto público, obligó a las universidades a imponer medidas de «sostenibilidad financiera» si querían acceder a transferencias con cargo a los presupuestos de las autonomías, las cuales intervinieron de hecho los gastos de las universidades incluidos, y sobre todo, las de personal.

${ }^{9}$ La media de edad del profesorado es escandalosamente alta como resultado de la falta la integración de las nuevas generaciones, como consecuencia de la falta de becas y de contratos de primera incorporación.
} 
la creación del Marco Europeo de Cualificaciones para el aprendizaje permanente). Gravemente preocupante es, pues, el protagonismo que se otorga al «aprender a aprender ${ }^{10}{ }^{10}$, es decir, adquirir competencias particulares para desenvolverse en el medio empresarial -training- de modo que la adquisición del conocimiento en sí, de los contenidos materiales, queda en un plano secundario. En realidad, es una lógica que responde a la dinámica empresarial que prefiere trabajadores dóciles y no conflictivos, subrayando aquellas competencias que aseguran la productividad del trabajador: las competencias

más valoradas por los empleadores, según informes realizados, son las denominadas competencias de personalidad, principalmente iniciativa, responsabilidad, disponibilidad, capacidad de adaptación al cambio y movilidad geográfica, saber desenvolverse en situaciones sociales y fácil inclusión en los grupos, presencia y aceptación de la autoridad (Moreno, 2009, p. 30).

Son similares los procedimientos pedagógicos en la Enseñanza Secundaria pública y que han determinado el desmoronamiento del acervo educativo y cultural de los alumnos que luego acceden a la Universidad.

Este lenguaje de la "pedagogía de las competencias», que parece convertirse en un fin en sí mismo en el sistema educativo ${ }^{11}$, suscita un cambio en el rol del docente que se ve desplazado de las clases magistrales, de su entidad presencial, para asumir una función de «facilitar el conocimiento- para que el alumnado-cliente se forme autónomamente. Éste se convierte en «estudiante inversor» que pretende rentabilizar la titulación obtenida (Moreno, 2009, p. 36).

Ahora bien, este entendimiento de la docencia universitaria provoca un giro en la estructura de los estudios universitarios hasta el punto de influir sobre la medición de los créditos en los que se distribuyen los ciclos de los Grados y los de las Asignaturas. Se introduce el lenguaje mercantilista de la Unión Europea en torno a los conocimientos: el "crédito ECTS» (European Credit Transfer System) como "unidad de medida común» del "haber académico» para diseñar las titulaciones en el marco del EEES. A diferencia de créditos que computan las horas de clase, de este modelo de medición debe incluir el número de horas de trabajo autónomo que se estima que el estudiante debe realizar para conseguir los resultados del aprendizaje previstos en las asignaturas de la Titulación. Un crédito ECTS representará entre 25 y 30 horas de trabajo y cada curso académico se compondrá de un máximo de 60 créditos (art. 4. Real Decreto 1125/2003, de 5 de septiembre), lo cual supone un total de 40 horas de trabajo semanales.

El detrimento de la calidad de la formación del alumnado se ha visto determinado también por los criterios de distribución de las asignaturas, no por

\footnotetext{
${ }^{10}$ Los pedagogos, por medio de las agencias nacionales y autonómicas, han pulverizado la enseñanza con una batería de lenguaje vacío y estúpido frente al cual el inolvidable "segmento de ocio" se constituye en inteligente recuerdo. Una y otra vez se idean impresos llenos de lenguaje que nada significa, pero que parece tiene la misión de aparentar un razonamiento profundo sobre la materia de que se trate. Ejemplo máximo de la vacuidad lo ofrece la ANECA con los expedientes que obliga a formar para acreditar titulaciones, en los que, una y otra vez, obliga a las universidades públicas a certificar que cuentan con baños, sistemas de calefacción, agua corriente..., con las especificaciones técnicas correspondientes, pero nada pregunta sobre la «inteligencia».

${ }^{11}$ Ésta ha sido la fundamental contribución de los pedagogos -no de todos, porque los hay conscientes de la problemática tras el sistema EEES, sino de aquellos oficialistas que han logrado hacer pingües negocios durante el tiempo de imposición del acervo de Bolonia, a costa de la enseñanza universitaria: durante estos años de "Asalto de la Peor Pedagogía» a la enseñanza universitaria, ha sido frecuente contemplar cómo personas subcontratadas que acaban de terminar su carrera universitaria impartían instrucciones sobre cómo «dar clases» y asumir liderazgo a avezados catedráticos con decenas de años de docencia. Véase García Amado (2009).
} 
semestres sino por cuatrimestres, que, en la práctica, se reducen a tres meses para titulaciones de 4 años como la de Derecho (que, incluso, en nombre de la competitividad y rentabilidad, se pretende en un futuro próximo reducir a 3), a lo que hay que añadir, a su vez, el recorte del número de horas teóricas. Una «fórmula anticalidad» que cabe completar con la masificación real de los grupos (al menos en Derecho) en las Universidades públicas que revierte contra todo atisbo de esperanza de una forma de impartir una docencia digna: no se ha reducido el número «efectivo» de alumnos en clase porque no ha aumentado el número de grupos. Precisamente éste debía haber sido el principal factor a combatir en la Universidad pública, pero la creación de más grupos comprometería la ampliación de la plantilla: actualmente, la ratio docente-alumnado sigue descompensada ${ }^{12}$. Supera con creces los 50 alumnos por grupo. No obstante, los indicadores oficiales (formales) disfrazan ese problema, porque no se contabiliza el número del alumnado repetidor, que, en asignaturas básicas de la Titulación de Derecho, como la «Parte General del Derecho penal», suele ser alto, arrastrando con ello el fracaso de las siguientes asignaturas penales; y lo mismo sucede con otras materias que tengan una estructura similar.

\subsection{El docente comprometido con el conocimiento también es víctima del sistema}

El proceso de adaptación al sistema EEES no sólo ha condenado al docente a una excesiva burocratización -no hay día que no haya que rellenar veinte complejos e inútiles papeles ${ }^{13}$ - , sino que se pone en cuestión el derecho fundamental a la libertad de Cátedra (art. 20.1. c. CE) (Vid. European University Association, 2005, p. 44) en torno a la metodología de la materia de la asignatura, las técnicas docentes y los métodos de evaluación. Problema que se acentúa cuando se comparte con otros docentes una asignatura que se distribuye en diferentes grupos: debe coincidir la guía docente en esos extremos.

Son muchos los obstáculos a los que debe enfrentarse el docente (bajo el múltiple perfil «docente-investigador-gestor-burócrata») si desea transmitir una enseñanza de calidad, tarea que deviene práctica y materialmente imposible, pues el docente responsable se opondrá a un contenido reductivo y simplificador de la formación, intrínsecamente contrario a una mínima idea de calidad de la enseñanza.

Esto debe interpretarse a la luz de lo que no ha sido más que una progresiva conversión de los profesores en «dadores de clases» cuya cualificación no importa ${ }^{14}$. Así, los mismos becarios, es decir, personas que acaban de terminar la carrera y se incorporan con becas de investigación a la Universidad, son encargados inmediatamente -constituye exigencia de su condición- de impartir clases, a pesar de su incipiente formación. Incluso, en esa distribución absurda que se hace de la

\footnotetext{
12 Es cierto que el número de estudiantes por grupo en los años 80, 90 y 2000, llegó a alcanzar, en las universidades grandes, hasta varios cientos de personas. Sin embargo, el nuevo sistema de Bolonia se construía, teóricamente al menos, sobre una reducción radical del número de estudiantes.

${ }^{13}$ Debe tenerse en cuenta que la política de ahorro de costes para obtener una mayor rentabilidad de las universidades públicas ha terminado con convertir buena parte del tiempo de los profesores en «tiempo administrativo», de esa forma se ahorra un puesto de trabajo de baja cualificación aunque sea a costa de emplear «tiempo investigador», mucho más cualificado, en «tiempo burocrático».

14 Belloso Martín (2009, pp. 244 y ss.) recoge una idea que nos parece importante subrayar: la del extraordinario/exagerado/poco realista grado de compromiso profesional que los nuevos «métodos y técnicas de estudio y de aprendizaje» requieren de docentes que, son al propio tiempo, no se olvide, investigadores y gestores. En efecto, en el EEES, el profesor universitario sigue desempeñando tareas investigadoras de las que depende su promoción profesional así como su financiación. El llamado sistema "Bolonia» parece concebido de espaldas a esa realidad o pensado para departamentos excedentarios o con poca carga docente, con personal capaz de actualizarse en relación a las teconologías de Información y Comunicación (TICs), de desarrollar la variedad de métodos y técnicas de estudio y de aprendizaje y de realizar tareas de investigación con el grado de dedicación que se exige en la actualidad: pero nada de esto existe.
} 
docencia, de acuerdo con la cual el profesor está en función de la organización y no al contrario, es corriente que el catedrático imparta las clases meramente prácticas y sea el becario recién entrado el que se ocupe de las clases «magistrales». Éste es el lamentable estado al que se ha llevado a la Universidad española.

El recorte de contenidos medidos por unidades ECTS encapsula, asimismo, los tiempos de enseñanza-aprendizaje y reduce los tiempos efectivos de docencia presencial. Pero no solo eso. También obstaculiza el desarrollo de la «vida universitaria más allá del Aula», más allá del periodo de docencia, que, sin duda, enriquece la formación universitaria. Hoy, promover la asistencia del alumnado a un congreso, unas jornadas, una conferencia o un seminario, requiere acudir a «estrategias premiales» (canje por créditos) o a una indeseada asistencia obligatoria por decisión del docente. Una situación que desmotiva la figura del docente como capacitador de vocaciones y de estimulaciones intelectuales, y que el propio sistema no computa como «dedicación académica» ni carga docente. El sistema está contaminado y presidido por la avidez de obtener con rapidez un título basado en el seguimiento fácil de «esquemas» y «apuntes».

En definitiva, asistimos en España a una concepción de la Universidad pública que se gestiona como una empresa, y que también ha mercantilizado la producción científica del docente-investigador, empobreciéndola hasta niveles verdaderamente insoportables.

La valoración de la actividad investigadora, que se reclama «al peso», también ha sido sometida a un enjambre burocrático, bajo la idea de la «meritocracia mercantil» en el acceso a las figuras docentes; la unidad de medida de la calidad de la producción científica se basa en el lenguaje de «percentiles» o «cuartiles» de la revista en la que se publica y el grado de «impacto", sin entrar a valorar, por parte de las agencias evaluadoras, la calidad del contenido de lo que se publica ${ }^{15}$. A lo que se une la necesidad de sufragar el coste de las propias publicaciones ${ }^{16}$.

2. Adaptación de la Universidad al sistema de mercado: la función de «educar» como herramienta

Bajo el prisma de la rentabilidad, la Universidad española camina al servicio de las demandas laborales y económicas, se orienta hacia la «empleabilidad» en un sistema de mercado de trabajo que es estructuralmente precario (sin hablar de las pruebas deficientes de acceso a la Judicatura o al ejercicio de la Abogacía en el caso de la carrera de Derecho). Un modelo de Universidad que se gestiona como una empresa preparada para reproducir esa reconocida precariedad colabora, a su vez, en el mantenimiento de ese statu quo. Se institucionaliza así la condición de precariedad a

\footnotetext{
${ }^{15}$ Muchos científicos e instituciones se están rebelando frente a este estado de cosas, un movimiento que impulsó la Declaración de San Francisco, DORA, que valora el impacto social y la relevancia del contenido de las publicaciones (https://sfdora.org/read/es/).

${ }^{16}$ Todo ello al margen de que reacias las autoridades docentes españolas a aceptar la crítica que, desde hace años, en todo el mundo, se ha dirigido contra las evaluaciones formales, ha tenido que ser una Sala, no especialmente progresista, del Tribunal Supremo, la de lo contencioso-administrativo, la que haya dictado una resolución según la cual «lo importante no es el envoltorio sino la sustancia»; ha tenido que ser el Tribunal Supremo quien se lo recordara a los gestores universitarios (STS, Sala $3^{a}$, 986/2018, de 12 de junio: «...las investigaciones, las aportaciones presentadas por los interesados, no pueden dejar de examinarse sólo por el hecho de que no se publicaran en las revistas o medios incluidos en los índices o listados identificados en la resolución de 26 de noviembre de 2014. Ni tampoco están excluidos por esa sola razón de la máxima valoración permitida por la Orden de 2 de diciembre de 1994. Dependerá de su contenido la evaluación que merezcan. Y a ello han de referirse el comité de expertos o los especialistas en los informes que emitan al respecto y en los que se fundamente la decisión de la Comisión Nacional de Evaluación de la Actividad Investigadora»).
} 
la que la mayor parte del estudiantado está abocado (Belloso Martín, 2009, ibídem.).

Por tanto, estamos siendo testigos de un sistema que encorseta el aprender, aderezándolo con el lenguaje de las «competencias y destrezas», y lo transforma en "educar». La función de la docencia queda reducida a la de "educar-sin cuestionar» bajo el eje del encapsulamiento de contenidos y tiempos. Un sistema que ha dejado en el exilio ese otro modelo del saber, de cuestionar y plantear alternativas. Viéndolo ahora con cierta perspectiva, se ha sustraído al alumnado de sus potenciales capacidades, la primera de ellas, la «curiosidad» como estímulo, además de la capacidad de construir y sistematizar pensamientos abstractos, de un «querer saber» más allá del aprendizaje funcional de mercado, incluso de poder pensar (reflexionar) un examen de contenidos sin la premura del lenguaje de test ${ }^{17}$. El alumnado se encuentra "milimetrado» en todas las facetas de una vida universitaria estructuralmente empobrecida: la vertiente de su trabajo autónomo también se encapsula. ¿Cómo asumir conceptualmente un modelo de Universidad que calcula y regula las horas de aprendizaje como si el estudiantado fuera menor de edad?

El objetivo es formar tecnócratas - de perfil «bajo» de contenidos genéricostras el eje de la meritocracia de cariz mercantil, una suerte de molde de fábrica recortado en serie. Una concepción funcionalista de la Universidad, que educa para mantener los objetivos y el sistema del mercado que discurre estructuralmente por líneas de precariedad en todos los órdenes.

Por ello, también, se ha excluido toda posibilidad de acudir al pensamiento crítico desde sus mismos cimientos, y eso se hace, sencillamente, a base de robar cualquier espacio para su formulación: las clases se han sustituido por un cronograma radicalmente empobrecedor, en el que hay que dar contenidos elementales bajo la espada del reloj, apoderando al mismo tiempo a los alumnos colaboracionistas para que denuncien inmediatamente al profesor que se salta la agenda de enseñanza. Aquí, los estudiantes han dejado de ser un factor de progreso para convertirse en el cemento con el que petrificar la enseñanza. A ello cabe unir una realidad que se comprueba todos los días en las aulas universitarias: el acervo cultural del alumnado que accede a la Universidad, por regla general, no hace más que decaer. El lenguaje fácil e inmediato de las redes sociales, el acceso al conocimiento «internet» indiscriminado que sustituye la consulta de una enciclopedia por Wikipedia, les aleja del manejo lento y reflexivo del formato de un libro. Lo único cierto de esta generación es que goza de la ventaja de ser capaz de entenderse en varios idiomas distintos del materno, pero ello no indica nada acerca de su acervo cultural.

Sin embargo, la Universidad es mucho más y distinto que la tarea de «educar». Aprender/enseñar "cuestionando» es la forma de acceder al conocimiento, bajo el enriquecimiento de perspectivas que analizan realidades; es la manera de aprehender capacidades y aptitudes críticas, adoptar un espíritu crítico. ¿Cómo hacerlo cuando se reducen contenidos, que quedan «encriptados» bajo la medición mercantil del tiempo de enseñanza y aprendizaje de los ECTS? Nos encontramos ante un estado de cosas que impide hoy sembrar las semillas para formar mañana grandes pensadores, filósofos, economistas, juristas, historiadores, etc., a pesar de que sabemos que es el pensamiento el eje del progreso, el motor de los cambios y el camino seguro hacia el

\footnotetext{
17 Obviamente, no puede olvidarse que el estímulo crítico ha dependido siempre del talante educativo de los profesores, y que, con un sistema u otro, si el profesor no se implica difícilmente el espíritu reflexivo llegará hasta los alumnos. Con todo, con el nuevo sistema, estructuralmente ese enfoque de enseñanza es inviable.
} 
bienestar $^{18}$.

La Universidad como modelo de transmisión e intercambio de saber no puede estar concebida para adaptarse al modelo de mercado, a una calidad que atiende a otros parámetros, tanto en la esfera pública como en la privada. Su existencia viene representada por su capacidad de transformar, de hacer progresar a la sociedad, por ser motor de cambios, y no al revés: ¿es el mercado el que transforma el modelo de Universidad? La calidad que mide hoy la Universidad es de naturaleza preeminentemente mercantil, que la ha precarizado en cualquier plano: la ha empobrecido en todos los órdenes.

Detrás del recorte «pedagógico» de contenidos de la Titulación y su sustitución por programas genéricos, se ha conseguido acumular bolsas (a-sintomáticas) de universitarios con serias deficiencias formativas. Una vez concluido el Grado en estado de precario, la especialización en la forma de Master no viene a compensar serias lagunas en el acervo del aprendizaje. Hoy, la baja calidad de la Abogacía, de la Judicatura, de la Fiscalía y de todas y cada una de las profesiones jurídicas en España, tiene un único y exclusivo origen: la pésima formación universitaria derivada de un deplorable modelo universitario, en el que se abandonan las humanidades (véase, ampliamente, Belloso Martín, 2017, pp. 17 y ss., especialmente pp. 35 y ss.; también Troncoso Reigada, 2017, pp. 81 y ss.) y únicamente se presta atención a la mecánica explicación del concreto epígrafe del reducido programa. Ni los Másteres, ni la Escuela Judicial, ni la Escuela de Estudios Jurídicos, convertirán por arte de magia a un estudiante de Derecho mal preparado (desde el origen) en un buen profesional. Ello no promueve sino el voluntario "autodidactismo» como tabla particular de salvación; y esta mediocridad formativa repercute directamente en la sociedad y en las expectativas de una ciudadanía de un país desarrollado.

En esta medida, particularmente en el caso de la Titulación de Derecho en la Universidad pública, asistimos a una "estafa de conocimientos», a un trueque falaz por "competencias y destrezas» sin un acervo formativo material de fondo, que no cabe atribuir al docente sabedor de su responsabilidad. Una estafa por liberalizar los Planes de Estudios, por liberalizar los precios de los Cursos de Master que se imponen para acceder a determinadas profesiones o a una cierta especialización, pues no solo profundizan en la desigualdad de oportunidades, sino que tampoco garantizan una formación integral mínima. El rostro de este estado de cosas revela tras de sí una forma de ningunear la importancia de las titulaciones en España, a pesar de la trascendencia social de su ejercicio, de todas ellas ${ }^{19}$. Un abismo en calidad y competitividad formativa nos distancia de modelos universitarios de países de nuestro entorno como Alemania, Francia, Italia, o Reino Unido, que han optado conscientemente, al menos en cuanto a algunas titulaciones como es el caso del Derecho, por mantener sus reconocidos sistemas universitarios y huir del EEES (García Mosquera, 2018).

\footnotetext{
${ }^{18}$ Ese radical desprecio a la inteligencia y al método se ha puesto de relevancia hasta en el combate a la peste que nos asola; en efecto, desde el primer momento del dictado del «estado de alarma», en lugar de haberse convocado a la «inteligencia» y reclamar a sus depositarios lo que «hiciera falta», se cerraron (con escasas excepciones) los laboratorios y se envió a los investigadores a sus casas. Allí siguen esperando los que hubieran podido haber ayudado a salir mejor de la situación. Frente al ¡Viva la Inteligencia!, el berrido de Millán Astray.

19 Aquí es donde, en realidad, radica la esencia del problema: para una sociedad que debe estar exclusivamente en función del actual modo de producción, sobran las filosofías y los latines (y en consecuencia llamaremos "cabrones» a los naturales de Cabra); pero, para una sociedad que piense siempre en progreso y en libertad del ciudadano, reclamaremos esas materias ( $y$ a los originarios de Cabra les denominaremos egabrenses). Historia, Sociología, Literatura, Latín, son materias esenciales para la formación del ciudadano; para el ganado lanar basta con pacas de alfalfa.
} 
3. ¿Una nueva reforma? Proyecto de Real Decreto por el que se establece la ordenación de las enseñanzas oficiales del Sistema Universitario Español (mayo 2020)

Lejos de plantear una necesaria reforma estructural del modelo universitario español, y reflexionar sobre las razones por las cuales países de nuestro entorno con clásicos modelos universitarios de calidad han renunciado a adoptar el sistema EEES en sus planes de estudio, el reciente (mayo 2020) Proyecto de Real Decreto por el que se establece la ordenación de las enseñanzas oficiales del Sistema Universitario Español irrumpe en un escenario de emergencia sanitaria para dar una vuelta de tuerca al modelo ya existente.

Tras reconocer que el proceso de adaptación del modelo universitario español al EEES «ha concluido», invita a actualizar el marco normativo que se emprendió en 2007 (Real Decreto 1393/2007, de 29 de octubre), poniendo de manifiesto la voluntad de afianzar este modelo formativo mediocre en su esencia (reducido en conocimientos) bajo el mismo prisma mercantil y aplicando criterios de rentabilidad:

se pretende robustecer las capacidades de empleabilidad que confiere la formación recibida en diferentes títulos, a partir de las competencias y conocimientos asumidos, o mediante las prácticas académicas externas en unos casos.

Bajo esta dinámica, parece querer impulsar Grados de 180 créditos ECTS, lo que significa insistir en una medida que hace años se rechazó en la Universidad Pública: $3+2$ años de Master a coste de un nuevo recorte de los contenidos mutilados de los Grados y más dosis de privatización, desigualdad de oportunidades y precarización en la formación universitaria. Con todo, mantiene el papel «clave» de vigilancia de la "calidad» en los criterios -que no cuestiona tampoco- de la ANECA: «la evaluación institucional de los centros se configura como una pieza esencial en el engranaje del aseguramiento de la calidad de la oferta formativa universitaria». Más de lo mismo, aunque se simplifiquen formalmente los procesos evaluadores y controladores de la vinculación de las enseñanzas universitarias con el mercado.

Es la garra del neoliberalismo al asalto de lo poco que en la actual «universidad» queda de Universidad: en efecto, "sí se puede» ir más allá en la mercantilización de la Universidad.

Pues bien, bajo este eje de «calidad» eufemística que pregona el Proyecto de Real Decreto, entra expresamente en escena la ANECA, amenazando con el desarrollo de una Estrategia "para el aseguramiento de la calidad en la enseñanza virtual" mediante la Implantación funcional del "sello de calidad de la enseñanza virtual" y el "sello de excelencia de la enseñanza virtual"» (ANECA, 2020). Estrategias que sólo cabe vincular, con el pretexto de la emergencia sanitaria, a una premisa con vocación para quedarse. Por otra parte, es una medida que genera una grave inquietud pues trata de aplicar «estándares de calidad» a la «enseñanza virtual», que es un método que solo puede concebirse para hoy y ahora, es decir: como una vía de escape frente a una situación sobrevenida de urgencia que no deja otra opción.

En síntesis, el Real Decreto 1393/2007, de 29 de octubre, por el que se establece la ordenación de las enseñanzas universitarias oficiales, que definió la estructura básica de la docencia universitaria española, hoy se muestra como «hito» de la desesperanza. Sin reformas estructurales, la Universidad pública española está condenada a ser sepultada. Veamos ahora el hilo conductor de su involución. 
4. De templo del saber a negocio indisimulado: la Universidad como una commodity más

\subsection{La instalación de las universidades privadas en España}

Los fondos de inversión, de pensiones, o simplemente buitres, no se habían acercado en España al «negocio universitario»; y ello por un motivo: no era rentable en términos económicos. Por ello, hasta hace un puñado de años, sólo la iglesia católica bajo diferentes personaciones (jesuitas, conferencia episcopal u opus dei) había desembarcado en los estudios universitarios; ella podía y, según su punto de vista, «debía» hacerlo porque, sin haber despreciado nunca el capital, como la experiencia histórica se ha encargado de demostrar, su rentabilidad se medía también en otra dimensión: la influencia. De hecho, ha tratado reiteradamente, a través de alguna de sus más poderosas garras fanáticas, señaladamente el opus dei, de «asaltar» (a veces con singular éxito) materias y escalafones en la Universidad pública. Mas, no cabe duda de que la inteligencia española-desde la derecha liberal- supo en todo momento limitar los daños: la resistencia que significados catedráticos españoles opusieron a la apertura de universidades por la iglesia en los años 60 del siglo $X X$, que, aunque no evitó la fundación de algún centro, sí los contuvo en su expansión.

Fue el Partido Socialista quien, en los años 90, abrió las puertas de la enseñanza universitaria al negocio privado. Esta iniciativa se vio fuertemente respaldada, a partir de 2001, por la Ley Orgánica de Universidades durante el Gobierno del Partido Popular, norma que incluyó a los directores de esas empresas privadas en el Consejo de Rectores y que reconoció a las universidades privadas «idénticas competencias» que a las públicas. Así, «universidades» como la Alfonso X el Sabio (1993), Antonio de Nebrija (1995), Universidad Europea de Madrid (1995), Francisco de Vitoria (1993), y, más tarde, otras con diversas denominaciones (no pocas eclesiásticas como las católicas de Ávila -1999-, Murcia -2000-, Valencia -2003), comenzaron a menudear en el panorama de la enseñanza superior en España (véase Simancas González y García López, 2016, pp. 173 y ss.). Algunas de las nombradas se han visto envueltas en escándalos ligados a la falta de titulación de alguno de sus dirigentes académicos ${ }^{20}$, o a la expendición de títulos en fraude (véase, verbigracia, Sánchez Juárez, 2015).

Tanta fundación de nuevas universidades tuvo mucho que ver con la extraordinaria reducción de las exigencias -en formación del profesorado, dedicación a la investigación, etc.- para fundar centros universitarios (el Ministro Wert redujo los requerimientos prácticamente a cero), lo que impulsó a que meras «academias» (centros adscritos se denominaban algunas) pasaran a ostentar el nombre de Universidad, y se constituyeran en centros de cierta atracción por las magníficas facilidades que ofrecían a los estudiantes para la superación de los cursos académicos.

Es llamativo que se haya permitido a centros privados incursionar en la Universidad, pero sólo para la parte del «negocio», sin realizar aporte alguno a la sociedad y, precisamente por ello, sin garantizar un mínimo de calidad de su profesorado: son las universidades sin investigación; el paso siguiente será el de, como paradigma, universidades públicas sin clases -o con pocas y no por razones de emergencia sanitaria, es decir: a distancia (el Proyecto de Real Decreto es el modelo que propone juniversidades a distancia con «sello de calidad»!); a

\footnotetext{
${ }^{20}$ Véase, verbigracia, Sánchez Juárez (11-11-2015): https://www.elconfidencial.com/sociedad/2015-1111/escandalo-en-la-universidad-antonio-de-nebrija-o-la-historia-del-decano-sin-titulacionuniversitaria 1091542/
} 
continuación, «universidades públicas laborales» construidas sobre el modelo de un bachillerato "profesional» volcado absolutamente en disciplinar a los trabajadores y con escasos contenidos intelectuales: esta etapa ya se está implementando, con unos grados, tal y como se ha indicado más atrás, radicalmente deteriorados en sus contenidos, y sobre los que están trabajando -para empeorarlos aún más- los «pedagogos oficialistas» bajo la mirada complaciente de los inversores que reclaman "más contacto con el mercado», "más prácticas»; el punto final consistirá en la expulsión real (más allá de ropajes formales) de las clases menos favorecidas de cualquier posibilidad de acceso a una enseñanza superior de calidad, que las permita mantener aspiraciones de mejora económica y social.

\subsection{Las nuevas «universidades basuras»}

Frente a la Universidad Pública dotada de centros de investigación reconocidos (por más que muy mejorables y pobrísimamente financiados) que han estado aportando a la sociedad española más del $70 \%$ del caudal investigador, se elevaban ahora las "universidades basura» (como la comida rápida de igual denominación), que prescindían -bajo mínimos- tanto de la investigación (reducción radical de costes) como de un profesorado de reconocida y contrastada calidad; si bien, no excepcionalmente, esas "universidades privadas» se sirven del crédito y buen hacer de funcionarios públicos docentes, universitarios o no, que imparten sus clases, en ocasiones, con flagrante conculcación de la legislación de incompatibilidades ${ }^{21}$.

A las anteriores universidades «tradicionales» se han unido otras -a las que más abajo se aludirá- con una metodología que desempeñaba un papel marginal en la Universidad española, más socialmente precisa (de la misma forma que lo ha sido la enseñanza "a distancia» en otros niveles), y que había llegado a ostentar un cierto nivel de calidad como consecuencia de que el régimen de selección del profesorado era igual que en el resto de las universidades públicas: la Universidad Nacional de Educación a Distancia (UNED). Una universidad que ha gozado siempre de un gran atractivo económico adicional para el profesorado, pues la cautividad de sus clientes en materia bibliográfica ha permitido una plena expansión por medio de la venta de manuales de crecido precio.

\subsection{La apuesta de los inversores por los estudios universitarios}

Sin embargo, todo lo anterior no era suficiente como para justificar un desembarco importante de capital privado, pues la rentabilidad seguía siendo escasa (de ahí los cambios accionariales en algunas de esas "universidades privadas») y únicamente inversiones «ideológicas» o de grupos financieros poderosos «trabajando a pérdidas», o con una ambición de expansión muy reducida ${ }^{22}$, podían seguir en la escena de la enseñanza superior. Hacía falta un paso cualitativo más, un movimiento importante de «reestructuración» de la Universidad pública que hiciera perder a ésta sus esencias de accesibilidad y calidad y crear un nuevo sustrato, para que los inversores se animaran a entrar en el negocio universitario. En definitiva, se precisaban dos claves: rentabilidad en la inversión y retornos financieros temporalmente reducidos.

El «sistema de Bolonia» vino a ofrecer las condiciones idóneas para esta fundamental etapa de privatización de la universidad, del comienzo de desaparición de la universidad pública y de la concepción de la universidad como un negocio,

\footnotetext{
${ }^{21}$ La excepción de calidad la han constituido algunas «escuelas de negocios» que verdaderamente han cobrado un merecido prestigio nacional e internacional.

${ }^{22}$ Como el caso de la Banca española a través de CUNEF, que sorprendentemente se encuentra ubicada en terrenos de una universidad pública donde desarrolla su negocio: nunca se sabrá cómo es que el Rector de la Universidad Complutense autorizó con un generoso convenio su instalación en su suelo.
} 
apartándola de las funciones que vino desarrollando durante muchos siglos, y que, en la España de los años 50,60 y 70, sirvió para que personas procedentes de las capas más humildes de la sociedad española se vieran elevadas a niveles de prestigio social y económico (véase, Langa-Rosado, 2020, pp. 164 y ss.).

La gran puerta de entrada del negocio privado en la enseñanza superior se ha efectuado a través de los Master. Cursos de uno (mayoritariamente) o dos años de duración, con un alto precio, a los que tienen que acceder inevitablemente los alumnos («clientela cautiva»), se constituyen en una excelente oportunidad de negocio, especialmente porque las universidades públicas no tienen capacidad de ofrecer «master para todos»; pero, además, porque, a través de los Masters a considerable precio, sobre todo los «profesionalizantes», las mismas universidades públicas obtienen los ingresos necesarios para mantenerse financieramente, tras la inquietante proclamación de nuestros dirigentes en materia de educación de que las universidades debían cumplir los mismos criterios de rentabilidad que las empresas.

Esa introducción de los Master como requisito (el 4+1 o el 3+2 que invocan ahora los adalides de la privatización), y la incapacidad de las universidades públicas para absorber todas las necesidades, (a lo que se une la paralización en la creación de centros universitarios públicos desde el año 1998) provocarán, a corto plazo, que en una estrategia apoyada por las comunidades autónomas donde gobiernan la derecha y la extrema derecha, por ejemplo Andalucía y Madrid- se termine ofreciendo a los centros privados universitarios el «cheque escolar» o la «enseñanza concertada»; es decir, la subvención indisimulada de los negocios privados universitarios. De esa manera se conectará la nueva reforma universitaria con la llevada a cabo en los años 80 por Maravall/Rubalcaba/Marchesi. Ese será el fatal desenlace de la enseñanza universitaria pública en España.

La ambición de los grandes grupos financieros ha sido satisfecha con el «sistema de Bolonia», pues, no en vano, el sector universitario constituye uno más de interés empresarial en el marco del mercado común ${ }^{23}$ : necesitaban "achatar» la duración de las licenciaturas para conseguir dos efectos: un retorno económico aceptable para sus inversiones (los cincos o seis años de duración de las licenciaturas en Facultades y Escuelas no es asumible para los financieros), y el establecimiento de un «régimen de cautividad estudiantil» que alimentara sus muy rentables Master; es decir, conseguir que estos estuvieran alimentados por estudiantes procedentes de sus propios centros y no solamente por los que la enseñanza pública no pudiera acoger en sus aulas. Factores que les permite una mejor planificación económica a medio y largo plazo.

Aquí, una vez más, el «modelo Bolonia» ejerció de guía de los intereses privados y diseñó los "grados" reducidos en relación a las licenciaturas, con los graves efectos que se han mencionado más atrás en relación con la formación de los estudiantes y su vocación de trabajadores sólo cualificados para la disciplina en el mercado. La limitación a cuatro años de los estudios de Grado (excepto de aquellos en los que los propios inversores "se jugaban algo", como es el caso de Medicina o Arquitectura), y la perspectiva de reducirlos a $3+2$ de Master, facilitó la transacción económica en varios sentidos: i) menos años para alcanzar un Grado atrae más a los clientes; ii) lo hace más accesible económicamente para estos; iii) posibilita un retorno

\footnotetext{
${ }^{23}$ No debe olvidarse que la Unión Europea es un mercado que nació como espacio para libertades de capitales y mercancías y, en su seno, todo responde a la lógica neoliberal de mercado que transforma lo que toca, ya se llame educación o salud. Vid. Supiot (2015), Enzensberger (2012), Naïr (2014) y, en particular, el interesante estudio de Ferreiro Bahamonde (2010, passim).
} 
económico a las inversiones razonable en el tiempo; iv) crea un amplio mercado de alumnos de Master que asegura la rentabilidad de las inversiones.

Este es el verdadero significado del «sistema Bolonia».

\subsection{La Universidad on line, pieza funcional del sistema: la muerte de la implicación del docente en la enseñanza universitaria}

Capítulo aparte merece la «enseñanza a distancia». Ya hemos referido cómo una cierta dosis de "universidad a distancia» es necesaria para cubrir necesidades sociales evidentes y no de mercado. Pero el panorama ha cambiado, en algún punto, mediante la fundación de alguna universidad de dudosa naturaleza (es el caso de la Universitat Oberta de Catalunya -UOC-, dependiente de dinero público, pero con funcionamiento al margen del sistema universitario público), determinada por un interés puramente mercantil (Universidad a distancia de Madrid, Universidad Internacional de la Rioja, Universidad Isabel I, Universidad Internacional de Valencia, etc.). Pero el alcance de la «universidad a distancia» llega mucho más allá: en realidad, se integra en una estrategia global controlada por el mundo anglosajón, especialmente por Estados Unidos, que concibe los servicios académicos, no sólo como un negocio, sino como una modalidad más de dominación de la mano de la denominada «lengua franca», el inglés. De esta forma, las universidades nacionales van perdiendo terreno con el impulso culpable de no pocos organismos internacionales ${ }^{24}$. Obviamente estas «universidades» exigen escasa inversión, únicamente una plataforma informática potente y materiales que se van repitiendo una y otra vez en todo tipo de cursos, y muy frecuentemente elaborados por docentes de escasa especialización profesional; a partir de ahí, unos «asesores» que se encargarán del contacto diario con los estudiantes, completarán toda la estructura. No hace falta decir que toda veleidad investigadora está al margen de semejantes estructuras.

Esta tendencia de autodestrucción de la Universidad pública se acentúa con las propuestas de elevar a norma, no a excepción, la Universidad on line, o la Universidad «de bolsillo» que se puede portar en el móvil: lo que debe ser nada más que un remedio perentorio para situaciones de necesidad (llámense «pestes» 0 condiciones personales que imposibilitan una asistencia personal), ahora tratan de transformarlo en paradigma. Es decir: aquí no se trata de un mero empobrecimiento de la Universidad, sino, sencillamente, del fin de un modelo, del traspaso de la universitas, en sentido propio, a la «academia de empleabilidad», si acaso.

Las nuevas doctrinas sobre la Universidad, entre otras las que alimenta el Ministro Castells, tratan de hacer de la enseñanza universitaria un ejercicio consistente en «educar» para el mercado, lo que significa domar, someter, dominar, creando un abismo con la perspectiva que permite al estudiante, en pleno ejercicio de sus derechos como ciudadano, capacidad de construir a partir de las herramientas que le facilitan sus profesores mediante una enseñanza crítica, apasionada, alejada de esquemas, tests y pantallas de espejismo universitario, de un espejismo de comunicación docente-estudiante.

Ese ejercicio neoliberal que, para la enseñanza universitaria, propone Castells se muestra de la manera más burda con la enseñanza on line, porque ésta es, por definición, encapsulada. Así, todo lo que signifique improvisación, ruptura de

\footnotetext{
${ }^{24}$ En realidad, el papanatismo universitario nacional está alcanzando cotas inimaginables: se llega a exigir en algunas universidades la docencia en inglés sobre materias en las cuales el mundo anglosajón ha contribuido en poco o en nada, lo que exigiría, incluso, la creación ex novo de todo un vocabulario técnico en esa lengua.
} 
esquemas, optar por vías inexploradas..., todo eso está ab initio excluido de una enseñanza tan encorsetada como la on line. Es la «Universidad en el móvil» del estudiante, un cambio de mentalidad que reemplaza al Aula universitaria y que es funcional al sistema, al paradigma de la rentabilidad. Representa, al mismo tiempo, un cambio del modelo de acceso a la enseñanza universitaria. La presencia cercana del docente en el Aula se metamorfosea en una suerte de comunicación deslocalizada, medida en unidades de pixeles encadenados de imágenes y voces diferidas.

En la docencia on line, a través del teletrabajo «doméstico», la implicación del rol del docente no es la misma. Se olvida que la presencialidad de la figura del docente en el aula, en su acervo investigador, no solo significa transmisión de conocimientos, también es transmisión de actitudes, de un lenguaje corporal que sólo se percibe en el aula -que se pierde en su ausencia, que se dilapida por las redes virtuales- y que suma un elemento más a la forma del aprendizaje, fundamental, porque esa figura presencial del docente vocacional promueve las motivaciones por aprender, por cuestionar -en tiempo real-.

\subsection{A modo de conclusión de este epígrafe}

Cierto es que la Universidad española nunca fue buena; tuvo períodos en los que pareció que llegaba a algo que pudiera conceptuarla como tal (aquélla época en la que el impulso de la Institución Libre de Enseñanza hacía sentir su influjo a través de múltiples instrumentos, como la Junta de Ampliación de Estudios), pero pronto esa llama se apagó de la mano del fascismo: buena parte de nuestros mejores educadores e intelectuales fueron asesinados, silenciados o tuvieron que marchar al exilio. Hubo que empezar, casi, de nuevo, y bajo la sombra de la sospecha (a eso, como es conocido, obedece la creación del Consejo Superior de Investigaciones Científicas como algo apartado de la Universidad ${ }^{25}$ ). Porque la corrupción acreció (las oposiciones patrióticas se adueñaron, en un principio, de los cuerpos universitarios, y el control ideológico se normativizó de la mano de la Ley de Ordenación de las Universidades de 29 de julio de 1943), pero, poco a poco, se abrió una cuña en tan empobrecido espacio intelectual y algo parecido a lo que podría ser una Universidad comenzó a forjarse; lo mejor: que se trataba (universidades pontificias, jesuíticas o de alguna facción religiosa, aparte) de una Universidad Pública. Lo peor: la corrupción y la mezquindad intelectual y política se adueñaron de las entrañas de un mundo universitario que no pudo despegar, a lo que se unió una carencia radical de inteligencia de muchos de los dirigentes educativos ya en la democracia, que desaprovecharon, una tras otra, todas las ocasiones de mejorar el modelo universitario en lo que ha parecido un campeonato de despropósitos. Lo que no impidió, sin embargo, que crecieran con fuerza no pocas «hojas verdes» ${ }^{26}$. El drama es que, con las excepciones que se quiera, cada decisión estructural ha sido más desgraciada que la anterior y lo preexistente, lo que parcialmente otorga la razón a autores como Fernández Buey (2009) cuando dice que «no hay nada importante que añorar de lo que fue la universidad del pasado». Mas la tragedia es que sabemos que las transformaciones que se están planificando en estos momentos para la Universidad española empeorarán en mucho el panorama actual, hasta el punto de llevar a la institución a la desaparición en sus esencias.

\footnotetext{
${ }^{25}$ Ley de 24 de noviembre de 1939, creando el Consejo Superior de Investigaciones Científicas.

${ }^{26}$ Es llamativo, por ejemplo, que España no haya tenido ningún Premio Nobel en ciencias duras desde Ramón y Cajal, ninguno. Pero peor aún: es que tampoco ha habido candidatos firmes, que es donde, realmente, se detecta el poder de la ciencia nacional. En cambio, países con mucha menor población que la española, con, teóricamente, inferior masa crítica, sí tienen candidatos habituales a los premios Nobel (es el caso de Suiza, por ejemplo).
} 


\section{La reducción de la duración de las licenciaturas y sus precedentes}

El plan de jibarización de las licenciaturas (que ya no lo son; incluso con el nombre se ha decidido abandonar «lo viejo») que propone el actual Ministro de Universidades, no constituye más que el enésimo ataque que sufre la Universidad pública española, por más que uno de los más graves, pues reproduce, sin ambages, la estrategia neoliberal que ha llevado como bandera el Partido Popular. Se enmarca en una línea ya anunciada en el año 2009 -«Estrategia Universidad 2015»- que llamaba directamente al reforzamiento de los consejos sociales (Ministerio de Educación, 2010, p. 45), alcanzando sus cotas máximas con la propuesta formulada en 2013 por un «Consejo de Expertos». Se proponía en éste la fusión del Consejo de Gobierno con el Consejo Social (Consejo de Universidad), en otras palabras, poner la gobernanza de las universidades, directamente, en las manos de las empresas (VV.AA., 2013), e imitar, sin tener sus activos, la estructura de las universidades estadounidenses, alejándose de la tradición de las universidades europeas. Ahora, con la «re-iniciativa» que ha puesto encima de la mesa el Ministro Castells, se profundiza en la misma idea.

Pero hubo dos anteriores ataques a la Universidad que deben reseñarse: uno que tuvo como diana a los estudiantes que llegan a la Universidad, y otro a la recluta del profesorado. Es decir, a los dos pilares sobre los que descansa una Universidad en el caso de las de «humanidades»: buenos alumnos y buenos profesores. En las de «ciencias» hay que unir «buenos equipos».

\section{La transformación de los estudiantes}

\subsection{Las pruebas de acceso a la Universidad}

En lo que importa a los estudiantes, y abandonado el viejo «preuniversitario», ningún sistema eficiente de selección de alumnos se implantó para acceder a la Universidad española: la supresión de las, también viejas, reválidas, significó la eliminación de la última barrera selectiva, como tal, antes de acceder a la Universidad. No hace falta más que ver los porcentajes de aprobados de la Selectividad en España para darse cuenta de que no sirve para nada, pues nada «selecciona» ${ }^{27}$. Otra cosa ocurre, por ejemplo, en el caso de Reino Unido y sus diferentes exámenes de nivel que son realizados al mismo tiempo en todo el mundo, pruebas que permiten que las universidades británicas ${ }^{28}$ se dirijan a los alumnos -antes, incluso, de realizar la prueba de selectividad final- con objeto de ofrecerles sus centros.

\subsection{Selectividad de «clase»}

Aquella realidad conduce a otra que acaba derivando hacia la Universidad un número desproporcionado de estudiantes, que, de antemano, se sabe que fracasarán en un alto porcentaje en los estudios universitarios, o en el ejercicio profesional postuniversidad, arrastrando a la enseñanza pública universitaria a un estado lamentable, y a la industria a dotarse de manos que no están suficientemente instruidas.

\footnotetext{
27 Más del $93 \%$ en la última convocatoria; véase http://www.ciencia.gob.es/portal/site/MICINN/menuitem.7eeac5cd345b4f34f09dfd1001432ea0/?vgnexto id=19729dddb339b610VgnVCM1000001d04140aRCRD

${ }^{28}$ Que son conocedoras de las calificaciones que van obteniendo los alumnos en esas pruebas «de nivel», alejándose así de la estupidez de las agencias de protección de datos españolas, que llegaron a prohibir, en algún caso como en Madrid, que se publicaran las calificaciones de los estudiantes en los correspondientes tablones. El resultado, como era de imaginar, fue el del secretismo de las calificaciones, la falta de publicidad, lo que permitió arbitrariedad y favoritismo sin control en las calificaciones.
} 
Todo ello constituye un error mayúsculo... a no ser que lo que se busque sea, exactamente, eso, que es la tesis que se mantiene en estas páginas por lo que importa a los estudios universitarios: un mercado laboral no especialmente cualificado que será el que nutran las clases menos favorecidas. Al lado de éste hallaremos una minoría seleccionada económicamente, que realizarán estudios de especialización en centros muy "selectos» (mayoritariamente extranjeros), y serán los llamados a integrar las élites (véase, al respecto, Bourdieu y Passeron, 2009, passim.). No estamos, pues, ante un error, sino ante un «plan».

\subsection{El Estado social abandonado}

A lo anterior se unen dos hechos significativos y gravísimos desde una perspectiva democrática.

Primero: mientras el Estado español se dedicó, desde la desgraciada aprobación de la Ley Orgánica 8/1985, de 3 de julio, reguladora del Derecho a la Educación, a subvencionar los colegios de la iglesia católica y otros grupos de interés económico, la enseñanza en las zonas económicamente más desfavorecidas quedaba, si no abandonada, sí insuficientemente atendida. Es decir, frente a las exigencias de que el Estado se volcara en la idea de convertir el acceso a la enseñanza en el necesario «ascensor social», la Administración focalizó sus esfuerzos en atender las necesidades financieras de las instituciones religiosas y grupos afines. Los nombres de Maravall, Rubalcaba y Marchesi siempre estarán vinculados a este gravísimo «hito» en el campo de la enseñanza.

Los efectos de esta política salvaje se hallan contrastados por numerosos estudios $^{29}$; en las zonas económicamente más pudientes, los resultados de los alumnos (tanto en centros públicos como privados -sean subvencionados o no) son mejores. A ello hay que unir, desde luego, otras variables: tanto por ciento en unos públicos- y en otros - privados- de personas socialmente desfavorecidas (entre otras, provenientes de la inmigración), profesorado asentado y compromiso del mismo, recursos, nivel cultural de los progenitores, acceso a los estudios, etc. Mas lo llamativo es que el Estado no haya hecho esfuerzos realmente significativos para revertir una situación que perdura a través de los años, mostrando de esa forma una «conformidad de clase» inaceptable desde una perspectiva diferente a la puramente neoliberal.

Segundo: el hecho de la supresión, en las enseñanzas básicas y medias, de todo filtro que actúe como tal, ha catapultado aún más la enseñanza privada, cuyos alumnos obtienen -no infrecuentemente- unas calificaciones en el bachillerato que no se corresponden con las que, posteriormente, consiguen en la prueba estatal. En otras palabras, las calificaciones de los estudiantes de los colegios privados parecen frecuentemente infladas, particularmente en algunos colegios especializados «en la última milla», en el último curso del bachillerato. Este hecho -no suficiente ni globalmente observado por los inspectores de enseñanza- se contagia también a los centros públicos que figuran en los últimos puestos de la relación ordenada de instituciones de enseñanza tanto públicas como privadas, lo que es un mal indicador, pésimo en realidad, de la política educativa desplegada por las instituciones estatales.

Desde luego, las consecuencias están bien claras: los estudiantes de la privada copan las mejores plazas en las universidades públicas, desplazando a los provenientes de las enseñanzas medias que cursan en instituciones estatales, y que

\footnotetext{
${ }^{29}$ Baste mencionar el realizado en Valladolid donde se pone de manifiesto lo ya enunciado. Véase Redacción de Valladolid (7-7-2019): https://diariodevalladolid.elmundo.es/articulo/valladolid/ricos-sacanmas-nota-ebau/20190707073000287600.html
} 
poseen iguales o mejores méritos; con la consecuencia de que estos últimos alumnos se ven forzados a cambiar de carrera y, a veces, de Universidad y población.

Lo anterior lleva a la paradoja de que la Administración prepara sus universidades públicas (que en términos de calidad siguen estando a años luz de las privadas, a pesar de los esfuerzos ministeriales para que suceda lo contrario) para atender, preferentemente, a los alumnos de los colegios privados.

\section{El cambio en el acceso a la función del profesorado universitario ${ }^{30}$}

\subsection{Introducción}

A la hora de instaurar un sistema de recluta del profesorado universitario en España se tiene que partir de un dato incontestable: en la sociedad española la corrupción se ha configurado como un rasgo estructural, por lo que se encuentra, desde hace muchos años, en claro declive moral. No es cuestión de precisar ahora el por qué, y tampoco es, de tan evidente, necesario justificarlo. Solamente apuntar ese dato. ¿Y la Universidad? No resulta obligado establecer un listado de qué institución española presenta mayor grado de corrupción, pero no cabe duda de que, en esa competición, la Universidad estará siempre peleando con autoridad por los puestos de cabeza, pues ya no es sólo cuestión de que a éste o a aquél le «quitaran» la cátedra. No, ese problema no es «el problema»: si en España se limitaran a «quitarles» la cátedra a los "unamunos» o a los «ramones y cajales» (aun cuando su frecuencia fuera mayor de la que es), el tema no sería, a pesar de todo, tan sumamente grave. La cuestión es la instauración de un sistema funcional (como sistema, no como mera anomalía del mismo) esencialmente corrupto y privado de cualquier mecanismo externo de control. Desde luego que las anteriores afirmaciones, como tendremos ocasión de comprobar, nos hacen llegar a la siguiente conclusión: cualquier sistema que se implemente para seleccionar el profesorado universitario en España debe prever y disuadir esos elementos «funcionales» y complementarse con un sistema de vigilancia estrecha de prácticas corruptas ${ }^{31}$. Hagamos, pues, un necesario recorrido histórico de criterios y procedimientos de selección del profesorado universitario en España.

\subsection{Historia antigua}

¿Qué ha sucedido con los sistemas de selección del profesorado ensayados en los últimos cincuenta años? El antiguo diseño de oposiciones (el anterior a las reformas de 1983) se desarrolló en el contexto de la Dictadura, con la obligada consecuencia de que los altos cargos ministeriales -directamente el Secretario de Estado de Universidades- ejercían cierto "control" sobre el Tribunal, y de hecho nombraban al Presidente de éste de acuerdo con intereses nunca confesados por más que obvios; además, los «sorteos» no infrecuentemente eran, de una u otra forma, «dirigidos» (lo que ocurrió, especialmente, cuando se informatizó su realización). Evidentemente, nada más hacerse público el resultado de los sorteos de los miembros de los tribunales, se podía aventurar el resultado, al menos de parte de las plazas, porque aquel viejo sistema reunía, entre sus ventajas, la de que se convocaran todas las plazas, con lo que, excluidas las ya «adjudicadas» por la vinculación entre miembros del tribunal y candidatos, aún había un sobrante por el que poder «pelearse». Pero ese viejo método de selección poseía también algunas virtudes: la primera de ellas era la que se derivaba directamente de la aplicación en su desarrollo de la publicidad. En efecto, los juristas sabemos de la capital importancia de este principio; de hecho, uno

\footnotetext{
${ }^{30}$ En lo que sigue se toma como referente el trabajo de Álvarez García (2013, pp. 139 y ss.).

${ }^{31}$ Las instituciones de abstención y recusación de los miembros "comprometidos" de los tribunales en relación a los candidatos, constituiría, sin duda, una buena práctica.
} 
de los primeros que es abolido en las Dictaduras (y en los regímenes autoritarios que lo son, aunque no lo parezcan) es justamente éste: el de la publicidad; ello llevaba a un doble control en las oposiciones: primero, que el opositor tenía necesariamente que cumplir unos mínimos y soportar el «tirón» de la oposición (seis ejercicios en las cátedras), afanándose en su preparación científica; y segundo; que los casos de radical escándalo en la adjudicación de plazas eran (los había, evidentemente) menguados.

A todo lo anterior había que añadir el hecho de que, al ser siete los miembros de los tribunales, la necesidad de justificar, en un debate directo con cada uno de los miembros de los mismos, la valía de la preparación y de la obra presentada, servía de barrera disuasoria a posibles aspirantes a las plazas que carecieran de la preparación precisa. De hecho, la mayor parte del profesorado universitario "sabía» que sus posibilidades de aspirar a una cátedra eran mínimas (también por razones de no contar con «apoyos» suficientes), con lo que la pirámide del profesorado era geométricamente perfecta (hoy es habitual que haya una proporción muy similar entre catedráticos y profesores titulares, incluso, en algunas universidades, una balanza "catedrática» mayor). En un sistema semejante, podían incorporarse a los cuerpos universitarios los mediocres, a veces los muy mediocres, pero difícilmente los absolutamente «ineptos»; incluso ese sistema permitió que represaliados por motivaciones políticas - que no fueron pocos más allá de los popularmente conocidosterminaran entrando en los escalafones, aunque, eso sí, exclusivamente apoyados por razones de adhesión personal al catedrático correspondiente, porque estructuralmente todo el sistema de acceso estuvo intensamente vigilado por el «régimen» hasta, al menos, la Ley General de Educación de 1970.

Por otra parte, debe subrayarse que las pruebas, las oposiciones, eran centralizadas, es decir, cuerpos «nacionales» de funcionarios, posibilitando que los candidatos fueran conocidos en todo el territorio $y$, una vez ganada la plaza -y como el resto de los funcionarios integrantes de cuerpos nacionales- «viajaran» por toda España antes de lograr consolidar plaza en las grandes universidades centrales (que eran muy pocas). Esto limitó enormemente la endogamia, al contrario de lo que sucede actualmente, y también evita una selección meramente localista de las plantillas universitarias, que es lo que sucede hoy especialmente en las universidades pequeñas.

Pero, más allá de lo acabado de señalar, un factor caracterizaba el sistema de recluta anterior a la Ley de Reforma Universitaria 11/1983, de 25 de agosto, que lo convertía en radicalmente injusto y democráticamente inasumible: la corrupción a la hora del dictado de las resoluciones de adjudicación de las plazas. Ese hecho -más allá de suponer el dictado de resoluciones injustas- provocaba algunos efectos absolutamente perturbadores que inhabilitaban el sistema para la función que tenía asignada: i) la necesidad imperiosa de pertenecer a un gran grupo, pues sólo esa condición podía llegar a asegurar que los miembros del mismo pudieran llegar a reunir los suficientes votos en un tribunal; esos "grandes grupos» se denominaban «escuelas», aunque frecuentemente esas agrupaciones tenían más que ver con banderías, con verdaderas "familias mafiosas» (Garrido Peña, 1999), que con una unión de docentes, investigadores e intelectuales que participaran en una misma dirección científica; ii) el establecimiento de relaciones de sumisión, y, en no pocos casos, de auténtica servidumbre ${ }^{32}$, entre el capo di scuola y los miembros de la misma;

\footnotetext{
32 Las anécdotas al respecto son incontables, labores de chófer, de paseador y vacunador de animales de compañía, de transportistas de los familiares del catedrático, de contertulio cuando aquél tuviera ganas de charla fuera la hora que fuese, de porteador de mercancías, etc., y también de sujetos pasivos de acosos y otras materializaciones sexuales -especialmente en el caso de las mujeres, y en este ámbito
} 
iii) la definición, con una extraordinaria frecuencia por parte del cabeza del grupo, de las líneas maestras científicas a las que había que adherirse, con lo cual cualquier atisbo de libertad de pensamiento científico se vio, en muchas ocasiones, seriamente abortado.

\subsection{La Edad moderna}

La Ley de Reforma Universitaria de 1983, más allá de un proceso de regularización inicial (las denominadas «idoneidades») que pretendía dar salida a un importante conflicto existente con los llamados «aprobados sin plaza», con los profesores más que capaces intelectualmente que no encontraban puesto funcionarial por la escasez de convocatorias y con las ingentes necesidades de profesores ante el alud de estudiantes que accedieron a la Universidad desde finales de los años $70^{33}$, introdujo un sistema descentralizado, en el que las convocatorias nacionales de plazas se vieron sustituidas por las locales. Cada Universidad convocaba sus plazas, y, con diferentes fórmulas y porcentajes, elegía parte del tribunal que debía juzgarlas, que era precisamente el adecuado al candidato para el que se solicitaba la plaza ${ }^{34}$. No hay que insistir mucho para señalar que del nuevo sistema se dedujeron inmediatamente dos efectos: i) endogamia y empobrecimiento de la calidad del profesorado, que es a lo que conduce la falta de competencia pues las plazas empezaron «a ser propiedad» de los habitantes de cada Universidad; ii) incremento del número de aspirantes, pues a los que tenían por vocación la carrera universitaria y asumían la necesidad de cambio de universidad y población, que era la inevitable consecuencia del «viejo sistema», se sumaron ahora los que, en ningún caso, estaban dispuestos a la migración y que reivindicaban como «derecho propio» el acceso a las plazas de «su» universidad.

Lo único que facilitó el cambio de sistema fue la realización de las pruebas a los aspirantes locales a las mismas, pues el número de los ejercicios y las dificultades de los mismos -señaladamente en las cátedras- menguó considerablemente. Sin embargo, las prácticas corruptas no disminuyeron, determinadas e intensificadas ahora por su localismo, y el grado de dependencia personal de los profesores respecto de los «jefes de escuela» tampoco aminoró. En otras palabras, se diseñó un sistema que, a lo malo de lo viejo, unió lo malo de lo nuevo. A partir de ese momento, los profesores abandonaron la trashumancia y se convirtieron en sedentarios.

Pero los continuos escándalos del nuevo método, y los malos resultados que propició, provocaron otro cambio en el método de selección del profesorado; así, la Ley Orgánica 6/2001, de 21 de diciembre, de Universidades, introdujo un sistema de habilitación nacional que incorporó, frente al anterior, novedades muy interesantes, pues reintrodujo el concurso nacional, el sorteo de todos los miembros del tribunal y pruebas orales, alejando, otra vez, el sistema de recluta del localismo, al tiempo que permitía que las universidades eligieran, entre los ya habilitados, el profesor que mejor les interesara. Cierto que no impedía por completo la corrupción del viejo sistema, esta vez atribuida a la corrupción personal de los miembros del cuerpo de catedráticos, pero la mitigaba de alguna manera. Porque el control que antaño ejercía el Ministerio sobre los tribunales había desaparecido; porque lo mismo sucedía con el de las propias universidades; porque al convocarse un relativamente alto número de plazas, siempre

todavía no se ha abierto el secretismo que ya ha comenzado a romperse en otros ámbitos, como el cine o el bel canto.

${ }^{33}$ Producto, también, de la supresión del preuniversitario y progresivo de las «reválidas».

34 Véase el Real Decreto 1888/1984, de 26 de septiembre, por el que se regulan los concursos para la provisión de plazas de cuerpos docentes universitarios; con este sistema, la Universidad convocante elegía dos miembros del tribunal, y bastaba con que, en el sorteo de los otros tres, saliera un miembro afín, lo que era relativamente sencillo si la «escuela» que impulsaba la convocatoria de la plaza tenía un tamaño «medio», para que los extraños a la universidad convocante no tuvieran nada que hacer. 
se le daba alguna oportunidad al "conocimiento» (triste consuelo, pero consuelo); porque al exigirse, incluso para plazas de titulares, el acuerdo entre los siete miembros del tribunal, las posibilidades de corrupción siempre eran menores.

Pero este sistema no estaba destinado a perpetuarse, pues inmediatamente atesoró enemigos, entre otros: i) los aspirantes a plaza de numerario que no estaban dispuestos a preparar una oposición exigente, o que sabían que no eran capaces de obtenerla; ii) las universidades y departamentos que querían ser los únicos en administrar su botín (las plazas); iii) las universidades privadas, que veían como tarea hercúlea -que requería además una buena inversión económica- que «sus» profesores pudieran llegar a habilitarse, factores que limitaban extraordinariamente las expectativas de extensión de su ámbito de negocio.

\subsection{La Edad contemporánea: sistema de acreditaciones ANECA}

Los factores acabados de mencionar propiciaron que se abriera un nuevo escenario en el mundo de la selección del profesorado universitario. Fue Ángel Gabilondo el ideólogo que proporcionó la llave ejecutora que guillotinó el sistema de las habilitaciones nacionales, para contentar a sus objetores que alegaban dificultades de implantación ${ }^{35}$, sin tener en cuenta sus amplias virtudes. Con ello se dio paso al sistema actual: las acreditaciones de la ANECA. Introducido por la Ley Orgánica 4/2007, de 12 de abril, por la que se modifica la Ley Orgánica 6/2001, de 21 de diciembre, de Universidades ${ }^{36}$, el nuevo sistema se ha caracterizado por otra suerte de prácticas: i) la clandestinidad en las evaluaciones, rompiendo con uno de los principios básicos en materia de recluta del profesorado: la publicidad; ii) la integración de «méritos» ajenos a la investigación y la docencia: las funciones burocráticas y puestos gestión se convierten en factor esencial para ser catedrático de Física o de Historia ${ }^{37}$; iii) dar prioridad a una encriptación formal de méritos, centrada en una apariencia externa que se mide al «peso», con independencia de la calidad «material» de lo aportado por los solicitantes de acreditación, valor no sometido a evaluación ${ }^{38}$, un sistema perverso porque, como es de sobra sabido, el instrumento de medición termina modificando el objeto mismo de observación; iv) uniformar el sistema para todas las enseñanzas, un "café para todos» en el que no se tienen en cuenta las diferencias de todo tipo entre las distintas disciplinas ${ }^{39}$; v) ruptura del principio de especialización de los saberes a la hora de valorar los méritos del solicitante, de manera que, componentes de la comisión evaluadora ajenos a la disciplina científica

\footnotetext{
${ }^{35}$ Excesiva duración de las habilitaciones, incremento del gasto, necesidad de desplazamiento de los aspirantes de sus lugares de origen a la plaza donde celebraba las sesiones el tribunal, etc.

36 Toda la explicación que la nueva Ley ofrece del cambio de sistema en el Preámbulo es la siguiente: «La selección del profesorado funcionario se modifica incorporando un modelo de acreditación que permita que las universidades seleccionen a su profesorado entre los previamente acreditados. Este sistema incorpora para el conjunto de la comunidad académica un mayor rigor en la acreditación y una mayor flexibilidad para las universidades en la selección de su personal».

${ }^{37}$ La publicación de la Ley generó una suerte de imagen caricaturesca: comenzaron, por arte de magia, a multiplicarse los puestos de responsabilidad en la estructura burocrática universitaria, y los catedráticos cedieron frecuentemente a los más jóvenes la dirección de los departamentos u otras unidades docentes o administrativas, para que estos lograran «acreditarse». Una acreditación al precio de restar tiempo valioso a la investigación y a la docencia.

38 Se dan otras situaciones que rozan el ridículo: en el caso del área del Derecho, las exigencias para obtener la acreditación, como contar con un cierto número de monografías, ha provocado que cada vez más se publiquen monografías de menos páginas o que éstas incorporen más apéndices, índices, etc. ${ }^{39}$ Resulta llamativo, en ese sentido, que los pedagogos «oficialistas» impusieran en las planificaciones que las carreras universitarias -todas- siguieran una determinada senda, y que, por ejemplo, las salidas al extranjero para incrementar la formación se realizaran tras las lecturas de las tesis doctorales, olvidando que existen materias en las que por decenios se había demostrado que lo más conveniente para la calidad es que las estancias de investigación se llevaran a cabo en un período anterior a la lectura de la tesis, lo que en un tiempo había llevado a los docentes de la materia en cuestión a ocupar alguno de los primeros puestos del mundo en la investigación.
} 
de aquel, juzgan su idoneidad docente e investigadora ${ }^{40}$; vi) disminución de la calidad en la dirección de las tesis doctorales -es decir, en el primer trabajo de investigación que inicia un aprendizaje decisivo para el porvenir de los investigadores-: su cualificada valoración como mérito (absolutamente "prematuro») precipitó a los más jóvenes «a los caminos armados de faroles» en búsqueda de personas a las que dirigir una tesis; vii) «autodidactismo», dado que el camino para la obtención de una acreditación está formalmente marcado y encapsulado, ajeno a criterios materiales de calidad, la carrera universitaria -al menos en algunas especialidades que por sus características lo permiten-se ha plagado de self made (wo)men, lo que, obviamente, implica un corte en la transmisión de los saberes, un empezar constantemente de cero; viii) la liquidación de cualquier prueba oral y pública; ix) evaluación dispersa entre las decenas de agencias autonómicas; $x$ ) creación de enormes bolsas de acreditados sin plaza; etc.

No obstante, cabe subrayar una sola virtud del sistema, que posee claro envés: el profesor pasa a tener un menor grado de dependencia personal del catedrático ${ }^{41}$.

Las principales consecuencias de este nuevo sistema de selección del profesorado han sido las siguientes: i) la ausencia de toda movilidad del profesorado y una endogamia atroz $^{42}$, al no estar sometida la acreditación a cambio alguno de universidad y depender la convocatoria posterior de la plaza del mismo departamento al que pertenece el docente; de esta forma, los profesores comienzan sus estudios universitarios en la misma universidad en la que terminan jubilándose; ii) promueve prácticas de corrupción hasta límites inimaginables desde cualquier otro sistema, pues ya no es necesario, siquiera, la «manipulación» de los tribunales juzgadores, dado que ese «trabajo» se efectúa desde la propia universidad al controlar el "grifo» de las convocatorias ${ }^{43}$, pues se atribuye a los departamentos convocantes la prerrogativa de proponer íntegramente el tribunal, el control absoluto de las plazas; iii) burocratización extrema del trámite de acreditación a través de un laberinto de procedimientos engorrosos: en este caso, los pedagogos "oficialistas» "se han empleado a fondo" y logrado que los solicitantes tengan que dedicar no menos de tres meses a rellenar las correspondientes instancias, o recurrir, como alternativa, a empresas especializadas que se lucran al amparo de los complejos trámites ANECA) ${ }^{44}$; iv) blindaje absoluto de las plazas de profesorado, hasta el punto de que las universidades han cerrado sus sistemas de convocatoria, acudiendo a un porcentaje, cada vez mayor, de plazas caracterizadas como de «promoción interna», a las que no puede presentarse nadie

\footnotetext{
${ }^{40}$ Habitual ha sido que las solicitudes de acreditación para profesores de Derecho hayan sido sometidas a la visión de una comisión en la que, de diez personas, sólo dos son especialistas en materia jurídica; el resto podían ser docentes en educación física, periodismo, economía..., eso sí, siempre bajo la mirada presente de un miembro de la Pedagogía, que terminaban decidiendo sobre la aptitud científica de un profesor en Derecho.

${ }^{41}$ Desde luego que lo dicho no significa que se vea totalmente libre de su influencia ello, porque, al final y en muchos casos, el apoyo de «sus» catedráticos puede facilitar la correspondiente acreditación: incluso habiendo méritos suficientes, según los baremos, la influencia sobre los miembros de la comisión de la ANECA hace más amable el camino. Que no todo transcurre prístinamente se ha expresado con claridad. Los distintos escenarios se mantienen abiertos: i) sólo la pertenencia del «jefe de la escuela» a la correspondiente comisión de la ANECA es capaz de explicar la acreditación de sus discípulos; ii) al contrario: los odios «de escuela» pueden impedir, paralelamente, la acreditación de personas con más que sobrados méritos.

42 De este hecho puede dar una idea precisa el bajísimo número de profesores ajenos a la universidad convocante que se «atreven» a firmar una plaza sacada a concurso por ésta.

${ }^{43}$ Lo que promueve, a su vez, la práctica de «congelación de plazas» hasta que el candidato local se encuentre "preparado» para adjudicarse la correspondiente plaza: nunca se había visto tanta corrupción en la Universidad como la que se ha derivado del control de las plazas por los propios departamentos convocantes.

${ }^{44}$ La vertiente positiva de este hecho se encuentra en la creación de empresas especializadas originando así un empleo «emprendedor» tan necesitado en España-, que de alguna manera se encargan de «filtrar» las solicitudes y de indicar al cliente los «méritos» en los que debe incidir.
} 
que ya ocupe el nivel respectivo en otra universidad ${ }^{45}$ : ahora sí, con este sistema, los premios Nobel, o los investigadores de reconocido prestigio nacional o internacional, carecen de toda oportunidad de ocupar una cátedra en la universidad española, y los traslados interuniversitarios también; v) una evidente disminución de la calidad del profesorado: cierto que, con el nuevo sistema, se han acreditado docentes universitarios que, por su valía, lo hubieran hecho de cualquier modo, pero también se posibilita, bajo la aplicación de criterios formales de méritos de calidad, la presencia de otros que, muy improbablemente, en unas oposiciones libres, nacionales y públicas, hubieran logrado alcanzar una plaza. Hoy, sin embargo, esos profesores no aptos para la carrera universitaria ya son titulares o catedráticos, y empujarán hacia abajo la docencia, la investigación... y la Universidad pública.

En síntesis, a la «nueva» Universidad española caracterizada por ser una institución cerrada y blindada localmente, se suma el mayor fruto de la Ley de 2007: la consolidación de los profesores de la universidad privada en pie de igualdad respecto de los de la universidad pública. Un gravísimo resultado que sólo podía ser logrado con un sistema de acceso a la acreditación muy devaluado.

\subsection{La precarización del profesorado universitario en la Universidad pública}

Cualquier joven lleno de vocación que quiera incorporarse a una envejecida Universidad como la descrita debe saber algo: con suerte, a los 40 años de edad podrá llegar a la figura de «contratado doctor» o a de «ayudante doctor»; hasta ese momento sobrevivirá con contratos precarios, debiendo desempeñar en la Universidad, por un salario miserable, una triple función: docente, investigadora y administrativa. No solo deberá buscar quién le financie los gastos universitarios, sino que tendrá que convivir con una pléyade de profesores «no académicos», que son quienes imparten mayoritariamente las clases en no pocas Facultades -asociados, falsos unos y verdaderos otros, pero siempre en precario- y con parte de personal docente «académico» desincentivado, que piensa en la jubilación anticipada como mejor opción si no logra pluriemplearse, y, todo ello, en un ambiente intelectual tan empobrecido como lo precisa el «Plan de Bolonia».

No resulta nada extraño, por lo anterior, que en las universidades esté ocurriendo, en materia de personal, algo parecido a lo que sucedió hace ya algunos años en los conventos: sólo quedaron monjas viejas que, además, no eran las más santas, aunque sí las más desvalidas ${ }^{46}$.

En efecto, resulta muy difícil lograr que jóvenes brillantes se incorporen a la Universidad pública, y ello por una potísima razón: la institución no es capaz de ofrecerles un futuro que siquiera se asemeje lejanamente, en condiciones y perspectivas, al que puede brindar una institución pública digna de serlo.

Somos testigos presenciales de una situación que está alejando de la Universidad a los mejores integrantes de las promociones universitarias...lo que es, insistimos, funcional al sistema de Bolonia, que no precisa ya a los profesores más brillantes impartiendo clases, sino a los más inagotables y polivalentes, que con frecuencia se encuentran en el ejercicio de otras profesiones y a quienes se les ofrece completar sus sueldos con pequeñas retribuciones universitarias. En este ambiente, la investigación se desvía a otros centros muy especializados y mal financiados, mientras que poco a poco va desapareciendo de las universidades; $y$, en los estudios en los que

\footnotetext{
${ }^{45}$ En esta tarea los sindicatos han tenido un protagonismo especial.

${ }^{46}$ Selección adversa que también aparece en los partidos políticos, lo que explica mucho de la calidad de nuestros dirigentes y de su desprecio por la Universidad, a la que únicamente se acercan con intereses, personal y colectivamente, cuasi-delictivos. Véase, nuevamente, Galaup (2019).
} 
esa fuga no es posible por las peculiaridades de las materias que se imparten, simplemente languidece, manteniéndose únicamente la que viaja a lomos del voluntarismo ${ }^{47}$.

Esta caída, buscada, de los servicios universitarios, abunda en la misma estrategia puesta en funcionamiento en otros campos, singularmente en la sanidad: el neoliberalismo ha ido, y no poco a poco, descapitalizando el servicio público y provocando una huida del profesorado universitario hacia otros quehaceres que les proporcionan mejores ingresos ${ }^{48}$. Se trata de una estrategia que ha sido combinada con la escasísima contratación en vocaciones universitarias, subcontratando, como se ha indicado más arriba, las labores docentes a bajo precio y menor cualificación en la inmensa mayoría de las ocasiones... y olvidando la investigación.

Esta es la semilla idónea para el auge de las universidades privadas, que les facilita un claro nicho de negocio que vaya más allá de una mera «guardería para niños ricos» a los que sus padres quieren mantener en un "ambiente selecto» por más que intelectualmente no gocen de reconocimiento alguno: cuanto más decaiga el nivel y dedicación del profesorado universitario, más fácil será a los negocios privados competir con la Universidad Pública; exactamente lo mismo que ha ocurrido, que está sucediendo, con los servicios públicos sanitarios (la diferencia es que en estos últimos también se exigen, por razones obvias, niveles de calidad, por lo que los políticos se han tenido que entregar con más fuerza para ir desmantelando la sanidad pública).

\section{A modo de breve conclusión: al rescate de la Universidad Pública española}

Al final de un periplo de apenas treinta años, el sistema neoliberal ha logrado lo que pretendía: convertir la educación universitaria en una oportunidad de negocio a través de un sistema muy devaluado pero que asegura no sólo retornos financieros prontos, sino también unos beneficios estimables y una influencia ideológica de primer orden en las nuevas generaciones: la iglesia católica y sus filiales, la banca, los fondos de inversión internacionales, etc., al igual que los «pedagogos oficialistas», se están "empleando a fondo». Y lo han conseguido -con apoyo interno y externo-, de la misma forma que en la sanidad pública o en las residencias de ancianos: a base de devaluar la calidad de la enseñanza pública para tratar de ponerla al mismo nivel que la privada ${ }^{49}$, para lo cual el sistema de Bolonia, con la reducción de la duración del Grado, la propagación de los sistemas de enseñanza on line, la generalización de la exigencia de cursar Master o la disminución de la calidad del profesorado, ha ofrecido el esqueleto estratégicamente adecuado.

\footnotetext{
47 Poco importa lo que nuestro tejido empresarial y el desarrollo económico del país hagan con la Universidad pública, lo que se pone crudamente de manifiesto con la más mínima crisis cuando los «motores tradicionales de nuestra economía» (turismo, construcción) se ponen al ralentí. El que ello sea así no lo impide el «triunfalismo investigador» que periódicamente invade a nuestras autoridades sobre la base del número de publicaciones científicas, que es desnudado lúcidamente en Rodríguez Navarro (2012 y 2013).

${ }^{48}$ En algunas especialidades, más del $50 \%$ de los catedráticos, al menos en las grandes ciudades, compatibilizan la universidad con otros trabajos privados que les aportan mejores ingresos; la consecuencia es que la universidad se va quedando poco a poco orillada y el $90 \%$ del esfuerzo lo vierte el profesor en el empleo que le proporciona el grueso de sus emolumentos. Téngase en cuenta, en este sentido, que en el campo del Derecho, por ejemplo, cualquier funcionario del Grupo A está mejor retribuido, y se le termina reconociendo un nivel funcionarial superior, que los catedráticos de universidad; es el caso de jueces, fiscales, técnicos de la Administración civil del Estado, letrados de Cortes, del Consejo de Estado, abogados del Estado, ..., y, por supuesto, los poderosos, retributivamente hablando, secretarios de Ayuntamiento. Si esto es así, ¿puede extrañar que los catedráticos huyan de la Universidad hacia otros menesteres?

49 De momento, ciertamente, no se ha conseguido, lo que tampoco inquieta a los empresarios de la enseñanza privada, pues lo esencial es que ese negocio se haya abierto a sus intereses financieros.
} 
Sobre ese sedimento turbio de intereses ha venido a gravitar ahora esta pandemia que padecemos y que hará caer el PIB, probablemente, en dos dígitos. Nos encontraremos con una nueva encrucijada como otras pasadas. Se puede tomar la misma senda que en la crisis del 2007: el cierre de no pocas unidades de investigación, la fuga, otra vez, de cerebros que tanto había costado repatriar en los años anteriores, el abandono de proyectos de investigación que habían exigido cuantiosas inversiones, el acusado envejecimiento de las plantillas y la pérdida de varias generaciones de universitarios; ... o podemos transitar justo el camino contrario, el que se orienta a formar un sustrato profundo de inteligencia y de un saber que perdurará a largo plazo, y que incluso permitirá sobrevivir con mayor solvencia a futuras pandemias.

Pues bien, es evidente cuál debe ser la senda que conviene a la Universidad pública $y$, por ende, al país, y es la que otras naciones de nuestro entorno adoptaron en la crisis económica anterior: aumentar la inversión en la Universidad pública, en la investigación. Una premisa que debe disuadir todo intento de recurrir a vías fáciles y engañosas: la creación de pésimos sustitutos de la concepción de una Universidad pública como tal, es decir, las «clases» on line, una suerte de «academias universitarias» que a lo único a lo que contribuyen es a disminuir la calidad de la docencia, a proletarizar a los egresados y a aumentar la influencia de los grandes propietarios internacionales de "servicios universitarios». Aprovechemos lo bueno que ya hay entre las ruinas de la Universidad pública actual -que todavía, inexplicablemente, es mucho- y demos el impulso que democráticamente es exigible: volver a activar la Universidad, permitir integrarse a los jóvenes brillantes vocacionales, fortalecer los verdaderos equipos de investigación, invertir en conocimiento. Ello permitirá, a corto plazo, liberar nuestro país de un modo de desarrollo económico equivocado -fácil- y empobrecedor. E invertir, a largo plazo, en formación, ciencia e investigación.

En conclusión: no sólo hay que rescatar la industria del turismo (España no se debe reducir al turismo y a la construcción), la hostelería, la pequeña y mediana empresa o la industria del automóvil. El más urgente plan de rescate tiene que ser el destinado a poner a flote la Universidad pública: el motor del progreso y del saber.

Por todo lo anterior, hay que diseñar un plan de Rescate Urgente para la Universidad Española (RUUE).

\section{Bibliografía}

Álvarez García, F.J. (2013). Debatiendo: La selección del profesorado en la universidad española. Eunomia. Revista en Cultura de la Legalidad, 5, pp. 139 y 158.

ANECA. (2020). ANECA al día, 1(2), 20 de abril de 2020.

Atienza Rodríguez, M. (2009). Reformatio in peius. Revista Notario, 26. Recuperado de https://www.elnotario.es/113-hemeroteca/revistas/revista-26/1540-reformatioin-peius-0-5887089749693023

Belloso Martín, N. (2017). De las universidades humanísticas a las universidades modelo de excelencia. Los desafíos de una educación humanista en el siglo XXI. En F. Puy Muñoz (coord.), La Universidad humanista en un mundo globalizado. Madrid, España: Reus.

Belloso Martín, N. (2009). La construcción del Espacio Europeo de Educación Superior -EEES- en las universidades españolas. Seqüência: estudos jurídicos e políticos, 30(59), pp. 219-251. 
Bourdieu, P. y Passeron, J.C. (2009). Los herederos: los estudiantes y la cultura (2a ed.). Madrid, España: Siglo XXI.

Enzensberger, H. M. (2012). El gentil monstruo de Bruselas. Barcelona, España: Anagrama.

European University Association. (2005). Tendencias IV: Universidades Europeas y la puesta en práctica de Bolonia. Recuperado de http://www.eees.es/pdf/TrendsIV ES.pdf

Fernández Buey, F. (2009). Por una universidad democrática. Escritos sobre la universidad y los movimientos universitarios. Barcelona, España: El Viejo Topo.

Ferreiro Bahamonde, X. (2010). Mercantilización y precarización del conocimiento: el proceso de Bolonia. En Edu Factory y Universidad Nómada (comps.), La Universidad en conflicto: capturas y fugas en el mercado global del saber. Madrid, España: Traficante de Sueños.

Galaup, L. (20 marzo, 2019). En la 'zona cero' del caso Cifuentes un año después. El Diario. Recuperado de: https://www.eldiario.es/sociedad/cristina cifuentesel master de cifuentes 0 879813058.html.

García Amado, J. A. (2009). Allí voy y que arda Troya [Entrada en blog]. Recuperado de: https://garciamado.blogspot.com/2009/10/alla-voy-y-que-arda-troya.html).

García Mosquera, M. (2018). Los estudios de Derecho en Alemania: un ejemplo de formación jurídica al margen del sistema de Bolonia. Revista Jurídica de la Universidad de León, 5, pp. 117-125.

Garrido Peña, F. (1999). Universidad y mafia: Una hipótesis sobre las actuales estructuras de poder de la universidad española. El Viejo Topo, 133. Recuperado de https://webs.ucm.es/info/uepei/mafia.html

Langa-Rosado, D. (2020). Sobre la impertinencia de las políticas austericidas: algunos efectos y reflexiones desde el ámbito de la universidad. Revista de Sociología de la Educación-RASE, 13(2)Especial, COVID, pp. 164-173.

Laporta San Miguel, F-J. (2010). Bolonia y los estudios de Derecho, dos puntos de vista (I): el proceso de Bolonia y nuestras Facultades de Derecho. Actualidad Jurídica Uría Menéndez, 26, pp. 7-13.

Ministerio de Educación (2010). Estrategia universidad 2015. Contribución de las universidades al progreso socioeconómico español 2010-2015. Secretaría General Técnica. Centro de Publicaciones.

Moreno, R., (2009). De la Declaración de Bolonia a la Estrategia 2015: el proyecto europeo neoliberal de mercantilización de la Universidad. En L. Alegre y V. Moreno (coords.), Bolonia no existe. La destrucción de la Universidad Europea. Hondarribia, España: Hiru.

Naïr, S. (2014). El desengaño europeo. Barcelona, España: Galaxia Gutenberg

Redacción de Valladolid (7 julio, 2019). Los ricos sacan más nota en la EBAU. El Mundo.

https://diariodevalladolid.elmundo.es/articulo/valladolid/ricos-sacan-mas-notaebau/20190707073000287600.html

Rodríguez Navarro, A. (12 diciembre, 2012). El fracaso de la investigación no permite cambiar el modelo productivo. El País. Recuperado de: https://elpais.com/sociedad/2012/12/11/actualidad/1355249460 317026.html.

Rodríguez Navarro, A. (30 enero, 2013). Las causas del fracaso de la investigación en España. El País. Recuperado de: https://elpais.com/sociedad/2013/01/29/actualidad/1359486694 275932.html.

Sánchez Juárez, A. (11 noviembre, 2015). La Universidad Antonio de Nebrija cesa a su decano sin titulación universitaria. El Confidencial. Recuperado de: https://www.elconfidencial.com/sociedad/2015-11-11/escandalo-en-launiversidad-antonio-de-nebrija-o-la-historia-del-decano-sin-titulacionuniversitaria 1091542/ 
Silió, E. (29 enero, 2017). El rector de los plagios se despide con críticas a la justicia «a golpe de titular». El País. Recuperado de: https://elpais.com/politica/2017/01/27/actualidad/1485557863 745427.html.

Simancas González, E. y García López, M. (2016). Historia de un secuestro: de la Iglesia a la Marca. Evolución histórica de la Universidad en España. Chasqui. Revista Latinoamericana de Comunicación,133, pp. 173-190.

Supiot, A. (2015). La gouvernance par les nombres. Paris, Francia: Fayard.

Troncoso Reigada, A. (2017). El estudio de las humanidades en la formación del jurista. En F. Puy Muñoz (coord.), La Universidad humanista en un mundo globalizado (pp. xx-xx). Madrid, España: Reus.

VV.AA. (2013). Propuesta para la reforma y mejora de la calidad y eficiencia del sistema universitario español. Recuperado de https://www.usc.gal/export9/sites/webinstitucional/gl/web/descargas/propuestasreforma.pdf 